\title{
A virada ideacional: quando e como ideias importam
}

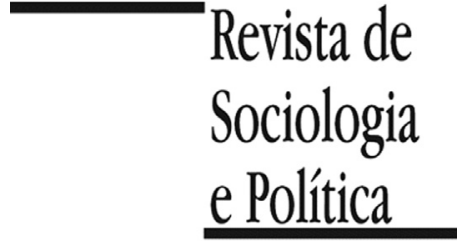

DOI 10.1590/1678-987317256403

\section{Renato Perissinotto e Michelli Gonçalves Stumm}

Resumo

O ensaio bibliográfico analisa a literatura que ficou conhecida como virada ideacional. Seu objetivo é, primeiro, resumir as críticas dessa literatura às perspectivas institucionalistas com as quais ela dialoga; segundo, sistematizar suas vantagens teóricas e, por fim, identificar o ferramental metodológico utilizado pelos autores que se filiam a ela. O ensaio baseia-se na análise de uma ampla gama de livros e artigos publicados sobre o assunto nos últimos 20 anos. Por meio dessa revisão bibliográfica, fomos capazes de mostrar como a literatura da virada ideacional permite incluir as ideias nas explicações dos fenômenos políticos. A inclusão das ideias, por sua vez, exige uma postura metodológica pluralista que pode significar avanços importantes para a ciência política.

Palavras-chave: virada ideacional; institucionalismo discursivo; construtivismo; comparação; process tracing.

Recebido em 1 de Novembro de 2016. Aceito em 8 de Fevereiro de 2017.

\section{Introdução ${ }^{1}$}

\author{
${ }^{1}$ Agradecemos aos \\ comentários e sugestões dos \\ pareceristas anônimos da \\ Revista de Sociologia e \\ Política.
}

partir dos anos 1990, ocorreu na literatura especializada em diversas
áreas (relações internacionais, políticas públicas, política econômica) o
que se convencionou chamar de "virada ideacional" (ideational turn) (Hay 1996; 2008; 2011; Goldstein 1988; Goldstein \& Keohane 1993; Berman 1998; 2001; 2013; Blyth 1997; 2001; 2002; 2003; Béland 2005; 2009b; 2010; Béland \& Hacker 2004; Schmidt \& Radaelli 2004; Schmidt 2010; 2014; Schmidt \& Thatcher 2013). Assumindo postura crítica diante dos limites explicativos dos diversos institucionalismos até então vigentes (escolha racional, histórico e sociológico), a "virada ideacional" defende que somente a inclusão das ideias dos atores políticos poderia explicar adequadamente os processos decisórios. Assim, em termos muito gerais, essa literatura defende que ideias importam.

Essa proposição, no entanto, não é nenhuma grande novidade. Os clássicos das ciências sociais são pródigos em defender tal premissa, com mais ou menos estofo empírico, em diversos trabalhos. Alexis de Tocqueville e Max Weber são, nesse quesito, dois exemplos incontornáveis. Max Weber é, aliás, o autor clássico mais citado pela literatura aqui revisada, em função da famosa passagem na qual o sociólogo alemão se refere às ideias como "manobreiros que determinam os trilhos pelos quais a ação é impulsionada pela dinâmica dos interesses" (Weber 1981, p.280). Não menos importante são as considerações de Tocqueville sobre os aspectos intelectuais da Revolução Francesa e o sentido quase religioso que a filosofia do século XVIII deu à Revolução ao pensar o homem abstrato e seus direitos universais (Tocqueville 2003). Mesmo no terreno menos fértil do marxismo clássico, não podemos esquecer as considerações de Engels, em carta a Bloch, sobre o papel desempenhado na história pela "tradição que perambula como um duende no cérebro dos homens" (Engels s.d., pp.284-285) ou as referências de Marx ao peso opressivo do passado sobre o cérebro dos vivos (Marx s.d., p.203). 
A importância concedida às ideias pelos clássicos prosperou em trabalhos de autores contemporâneos e foi radicalizada, por exemplo, no pensamento de Talcott Parsons. Segundo J. Hall (1993), Parsons teria levado essa proposição às últimas consequências, a ponto de pensar a coesão social estritamente a partir de fatores normativos. O grande adversário de Parsons no Departamento de Sociologia de Harvard, Barrington Moore Junior, também colocou no centro de suas preocupações o papel das ideias em uma brilhante análise sobre a política soviética (Moore Jr. 1951). Em meados dos anos 1970, mais especificamente na área de políticas públicas, surgiram trabalhos seminais e de fôlego empírico talvez insuperável, como os de Kingdon (2014) e Heclo (1974).

Portanto, afirmar que ideias importam apenas reitera posições há muito tempo estabelecidas nas ciências sociais e permanece no terreno da mera plausibilidade (Rueschemeyer 2006). Como observa J. Hall (1993), qualquer visão estritamente "materialista", "que vê as crenças, quando muito, como um disfarce sem importância para os interesses, é uma posição altamente implausível, na medida em que sugere que o curso da história humana teria sido idêntico, mesmo que o paganismo, as religiões mundiais e o marxismo nunca tivessem sido inventados" (J. Hall 1993). No entanto, por mais plausível que seja a proposição de que ideias importam para a plena explicação dos outcomes políticos (Goldstein \& Keohane 1993, p.29), sua operacionalização efetiva exige ir muito além dela (Hochschild 2006).

O objetivo deste artigo é apresentar a literatura produzida recentemente sobre o assunto e mostrar como a proposição geral de que ideias importam é operacionalizada em trabalhos empiricamente orientados. Para tanto, o presente texto se divide em cinco partes, além desta introdução. Na primeira, apresentamos resumidamente o diálogo crítico com as teorias institucionalistas que deu origem à virada ideacional. Na segunda parte, procuramos sistematizar, segundo a literatura, os ganhos teóricos que teriam permitido à virada ideacional superar os limites das vertentes institucionalistas identificados na seção anterior. Em seguida, mostraremos ao leitor o que são ideias, com ênfase nas tipologias e hierarquias desenvolvidas pela literatura. Nas quarta e quinta partes discutiremos quando e como ideias impactam nos resultados de políticas públicas e quais os procedimentos desenvolvidos para verificar esse impacto. Por fim, à guisa de conclusão faremos uma breve síntese dos avanços para a ciência política que essa literatura propicia.

Em vez de uma apresentação cronológica e meramente sequencial, optamos por discutir a literatura de maneira a sintetizar seus eventuais ganhos teóricos e metodológicos. Por essa razão, o texto não se detém demoradamente sobre alguns poucos trabalhos exemplares, mas, ao contrário, lida com um amplo leque de livros e artigos, sempre enfatizando as suas estratégias metodológicas, as técnicas de pesquisa utilizadas e os seus pressupostos epistemológicos. Ao fazermos isso, autores de diversas correntes e que escreveram em momentos distintos serão apresentados conjuntamente por se colocarem problemas de pesquisa convergentes. Acreditamos que, dessa forma, entregaremos ao leitor um texto mais útil, contribuindo para trazer ao público brasileiro uma discussão que, em nossa opinião, está longe de receber a merecida atenção ${ }^{2}$.

\section{Ideias e neoinstitucionalismos}

2 Embora a atenção dispensada ao tema no Brasil tenha aumentado consideravelmente (ver, por exemplo, Aragão 2011; Barcelos 2015; Costa 2011; Grisa 2012; Lukic \& Tomazini
Estudos sobre o impacto das ideias, tal como arquitetado pelos principais autores que se dedicaram a esse tema a partir do final dos anos 1980, constitui-se, antes de mais nada, em análises institucionalistas. Na verdade, a questão geral presente na maioria desses estudos, sejam eles vinculados ao institucionalismo histórico (IH), ao institucionalismo de escolha racional (IER) ou ao institucionalismo sociológico (IS), consiste em saber como as ideias, mediadas 
2014; Rocha 2011; Sumiya 2015; Tomazini \& Leite 2016; Alston et al., 2016).

Mencione-se ainda o trabalho pioneiro de Sola (1998), baseado no não menos pioneiro trabalho de Hirschman (1979).

\section{II.1. Críticas ao IER}

\footnotetext{
3 A crítica às teorias institucionalistas apresentadas a seguir foi retirada da literatura vinculada à virada ideacional e não expressa necessariamente a posição dos autores deste ensaio. Para um resumo das posições institucionalistas a partir dos seus defensores, ver os incontornáveis artigos de Hall \& Taylor (2003), Immergut (1998) e Steinmo \& Thelen (1994). Para uma visão mais recente, ver Mahoney \& Thelen (2010).
}

por instituições, são importantes fatores explicativos de fenômenos políticos ( $\mathrm{P}$. Hall 1986; 1989; Goldstein 1988; 1993; Goldstein \& Keohane 1993; Sikkink 1991; Steinmo et al., 1992; Thelen \& Steinmo 1994).

Para alguns autores, contudo, a virada ideacional contida nesses institucionalismos não foi completa. As ideias teriam aí papel pouco importante, sendo as instituições o ponto central de seus argumentos. Nesse sentido, o interesse renovado dos neoinstitucionalistas pelo impacto das ideias sobre os resultados políticos não teria se traduzido em avanços teóricos e metodológicos. Como observa Blyth (1997), ideias continuaram tendo lugar secundário e dependente nessas teorias, que a elas recorrem apenas para preencher suas próprias lacunas, "em vez de tratá-las como objetos de investigação de direito próprio".

Por isso, os autores que pretenderam radicalizar a virada ideacional (Béland 2005; 2009b; 2010; Blyth 2002; 2003; 1997; Hay 2008; 2011; Schmidt 2008; 2010; Yee 1996) elaboraram diversas críticas às vertentes institucionalistas, mesmo quando estas buscavam incorporar as ideias em seus esquemas explicativos. A seguir, apresentamos tais considerações a cada uma das correntes teóricas institucionalistas ${ }^{3}$ e, seguindo a sugestão de Blyth (1997), veremos como as críticas vinculam os limites dessas vertentes às suas respectivas definições de instituições.

Todos os autores que defendem a incorporação das ideias em explicações de fenômenos políticos criticam as versões mais radicais da teoria da escolha racional. Mesmo Goldstein \& Keohane (1993), identificados por seus críticos como pertencentes a essa corrente teórica, afirmam que a visão estritamente "materialista" da teoria da escolha racional é simplesmente equivocada por duas razões. Primeiro, porque, ao contrário do que sugerem seus adeptos, não existem interesses "objetivos" que possam ser definidos a priori. Interesses são sempre lidos a partir de ideias e representações. Em segundo lugar, porque tais teorias não conseguiriam explicar porque, em jogos de múltiplos equilíbrios possíveis, atores estratégicos escolhem um em detrimento de outros. Como atores que se encontram em posições sociais semelhantes escolhem caminhos diferentes, os interesses partilhados por eles não poderiam fornecer a explicação dessa diferença. Somente a inclusão de ideias poderia solucionar esse problema. No entanto, para críticos de Goldstein \& Keohane (1993), é exatamente nesse ponto que se encontra o problema.

Como observa Blyth (1997), para os institucionalistas da escolha racional que defendem a inclusão das ideias em seus esquemas teóricos, instituições são apenas meios para reduzir custos de transações e ideias constituem-se em meros instrumentos a serviço de indivíduos atentos à maximização de seus objetivos. Essa perspectiva fica particularmente evidente nos conceitos de road maps e focal points apresentados por Goldstein (1993) e Goldstein \& Keohane (1993) e nas análises de Ikenberry (1993) e de Krasner (1993).

Segundo Schmidt (2010), especificamente nesse ramo do neoinstitucionalismo, a incorporação das ideias não teria avançado porque nele se apresentam apenas como mecanismos para escolha entre diferentes interesses, como pontos focais que permitem mudança de equilíbrio ou como justificativas a posteriori para escolhas baseadas em interesses. Ainda de acordo com a autora, a virada ideacional do institucionalismo de escolha racional foi logo abandonada porque tendia a negar de forma demasiadamente radical a separação entre interesses objetivos e a percepção subjetiva desses interesses. Tal processo ameaçava "sobrecarregar os objetivos que são a base do modelo de racionalidade fraca dos 
racionalistas, minando a natureza 'fixa' das preferências e a noção de que os resultados são uma função de preferências prévias" (Schmidt 2010). Sem preferências fixas e estruturas institucionais de incentivos, os adeptos do IER perdem a parcimônia de sua abordagem e tudo que segue dela, incluindo a capacidade de modelar matematicamente os jogos entre atores racionais. Assim, incluir as ideias como variável explicativa resultaria em abandonar os pilares centrais da teoria.

\section{II.2. Críticas ao IH}

O IH teria avançado na virada ideacional quando comparado com a vertente anterior. Nessa concepção teórica, instituições são encaradas de duas maneiras interligadas. Primeiro, continuam a ser vistas como constrangimentos à conduta dos atores, mas não mais apenas como um conjunto de regras formais às quais reagem racionalmente. Mais do que isso, são constrangimentos porque formam preferências e, desse modo, instauram práticas sociais regulares e duradouras que afetam o comportamento dos agentes. Segundo, ao definir instituições como formadoras de preferências que instauram práticas regulares, o IH foca necessariamente em questões de path dependence, isto é, em processos pelos quais instituições levam os atores a fazer escolhas dentro de determinados parâmetros ideacionais e como essas escolhas condicionam decisões futuras. Nesse sentido, trata-se de pensar não apenas uma path dependence institucional, mas também uma path dependence ideacional (Yee 1996; Crawford 2006).

Porém, exatamente por colocar ênfase nas instituições, os autores vinculados ao IH são criticados por três motivos. Em primeiro lugar, preocupados em pensar instituições como constrangimentos, os teóricos do IH teriam dificuldades para explicar processos de mudança social. Tendo como objeto central de suas análises a reprodução da ordem, buscam sempre padrões regulares de comportamento determinados pelos constrangimentos institucionais herdados (path dependence). Desse ponto de vista, não conseguem pensar a mudança institucional e política, a não ser apelando para variáveis exógenas ao modelo (punctuated equilibrium). Mesmo o conceito de "mudança de terceira ordem", formulado por P. Hall (1993), tenderia a pensar a mudança de determinada política apenas como alteração brusca, e não incremental, provocada por fatores externos ao processo decisório, como, por exemplo, a crise econômica que forçou, na Grã-Bretanha, a queda do keynesianismo e sua substituição pelo monetarismo no final dos anos 1970. Os críticos sugerem que atribuir maior centralidade a ideias poderia contribuir para "endogeneizar" plenamente a explicação dos processos de mudança em políticas públicas (Lieberman 2002; Béland 2005; Hochschild 2006; Schmidt 2010; Kangas et al., 2014) e em instituições (Ferejohn 1993; Novelli 2001).

Em segundo lugar, assim como o IER, o IH não avança muito na virada ideacional. Mais do que isso, conclusões a respeito do papel de ideias tendem a ser pouco empolgantes. Como menciona Jacobsen (1995), o livro de P. Hall (1989), por exemplo, não discute de maneira contundente o "poder das ideias", mas apresenta uma "mistura, ainda que efetiva, de análises institucionalistas" e chega a uma conclusão trivial: quanto mais poderosos os defensores de uma ideia, mais poderosa é a ideia, proposição idêntica àquela encontrada nas primeiras páginas do livro de Gourevitch (1986). Enfim, há pouca análise sobre o impacto de ideias propriamente dito e mais sobre sua institucionalização e aceitação social (Blyth 1997; Yee 1996).

Em terceiro lugar, enquanto o indivíduo do IER é hipossocializado, o do IH é, ao contrário, hiperssocializado (Béland 2009b; Blyth 1997). As instituições são grandes parâmetros formadores de preferências que criam legados institucionais que, por sua vez, afetam os processos de formulação de políticas 
públicas. O problema é que isso pouco nos diz sobre quais objetivos os atores políticos detêm em determinado momento e que tipo de objetivos ideacionais esses atores carregam consigo para além de parâmetros institucionais mais amplos. Isso é importante, pois dificilmente se pode explicar o conteúdo ideacional de agentes apenas se referindo aos legados de políticas e instituições. O processo decisório não é marcado apenas por legados institucionais, mas também por ideias que atores usam para convencer os demais (Béland 2009b). Nas palavras de Blyth (2001), ideias são usadas em processos decisórios como "armas" de luta e convencimento e, nessa condição, visam estigmatizar e redefinir antigos paradigmas e promover mudanças. Como o indivíduo do IH é hiperssocializado, essa corrente teórica tende a dar atenção apenas a momentos de fim da normalidade política e de mudança radical, já que fora deles as ideias não possuiriam quase nenhum papel inovador (Blyth 1997).

\section{II.3. Críticas ao IS}

Outro avanço na virada ideacional é representado pelas considerações do chamado Institucionalismo Sociológico (IS). Como observa Campbell (1998), enquanto o IH se preocupa fundamentalmente em saber como "constrangimentos institucionais medeiam a influência das ideais na política", dando pouca atenção a como tais ideias podem constranger o processo decisório, o IS enfatiza que, em ambientes de profunda incerteza, agentes políticos se apegam a "estruturas cognitivas", quase sempre inconscientes, que fornecem categorias mentais e viabilizam (e não apenas constrangem) a ação social. Nessa perspectiva, instituições não são apenas limites, já que representam um conjunto de formas e procedimentos procedentes de práticas culturais específicas; são normas, enquadramentos cognitivos, roteiros e sistemas de significados que guiam a ação humana seguindo uma "lógica de adequação" (logic of appropriateness) (Schmidt 2010).

De acordo com Campbell (1998), há dois problemas com essa perspectiva teórica. Em primeiro lugar, seus autores falham em especificar o processo causal pelo qual rotinas viabilizam a ação e, por conseguinte, afetam os possíveis resultados de um processo decisório. Em segundo lugar, os indivíduos também parecem ser hiperssocializados. Nesse sentido, o IS também tende a desprezar o uso consciente, deliberado e estratégico das estruturas cognitivas, por meio de um processo de "bricolagem" (recombinação de conceitos legítimos já disponíveis) e de "transposição" (uso inovador de soluções já usadas em contextos anteriores). Apesar disso, o IS constitui-se na vertente mais próxima do chamado Institucionalismo Discursivo (ID), corrente mais radical no que diz respeito à inclusão de ideias em explicações sobre políticas públicas. Tanto no IS quanto no ID ideias assumem o papel de viabilizadoras da ação. No entanto, a grande diferença da última corrente foi, segundo seus defensores, ter desenvolvido uma visão menos estática do papel das ideias, conferindo-lhes assim mais autonomia na explicação dos processos decisórios (Campbell 1998). Vejamos os principais avanços dessa corrente, segundo seus defensores.

\section{Vantagens teóricas do ID}

O objetivo fundamental do ID é superar os limites apontados acima. Em vez de enfatizar instituições e coalizões políticas, isto é, circunstâncias que favorecem o impacto causal de ideias, o objetivo recai sobre as ideias propriamente ditas. O ID ou Construtivismo, como às vezes é chamado, tem, segundo Cox (2001), origens que remontam a Max Weber e com frequência aparece sob a insígnia de "interpretativismo", "hermenêutica" ou "estruturação". Suas principais vantagens são discutidas a seguir. 
III.1. Autonomia de ideias perante interesses

A virada ideacional promovida pelo ID permitiria sair da cilada dos "interesses objetivos" ao reconhecer o impacto das ideias sobre os desejos dos atores. Desse ponto de vista, o ID recusa a proposição de que interesses objetivos, derivados automaticamente de localizações estruturais, produzem, por si só, preferências que, por sua vez, afetam a conduta. Esse tipo de posição teórica, que poderia ser encontrada tanto no IER como no IH, não percebe que interesses não existem por si só, não emanam "automaticamente" nem de posições objetivas no mundo social nem de qualquer propensão supostamente natural dos seres humanos à ação maximizadora. Interesses são, antes de tudo, constituídos pela percepção que os agentes têm acerca de si próprios e de sua posição no mundo (Price 2006; Cox 2001). Nas palavras de Hay (2011), "interesses não existem, mas sim construções de interesse", ou, dito de outro modo, "são as concepções que as pessoas têm de si e do mundo ao redor que as leva a conceber seus interesses de um modo particular" (Hochschild 2006). Ao adotar essa postura, a teoria se habilita a tomar as respostas subjetivas à realidade material como seu objeto de pesquisa (Schmidt 2011). Para ela, as preferências não podem ser simplesmente tomadas como dadas, mas devem ser explicadas.

Tal posição é, segundo seus defensores, um avanço diante dos demais institucionalismos por permitir pensar que instituições similares podem produzir efeitos muito diferentes, já que as crenças de seus operadores são distintas. Como não se trata de defender uma posição puramente idealista, o ID reconhece a importância das posições sociais como fator que afeta desigualmente a distribuição de recursos e poder na sociedade. No entanto, recorrendo a Max Weber, o ID insiste que tais "situações de interesse" são interpretadas e reinterpretadas a partir de ideias que, por sua vez, são lidas e relidas a partir das situações de interesses.

Ainda que nem sempre explicitamente vinculados ao ID, inúmeros trabalhos seguem essa orientação (Hay 2011; Heclo 1974; Blyth 2001; 2002; 2003; Schmidt 2010; Kingdon 2014). Goldstein \& Keohane (1993) e Blyth (2003), por exemplo, enfatizam como a conduta dos Estados deriva não apenas de suas posições de poder no sistema de relações internacionais, mas também das "identidades estatais" historicamente construídas e do modo como tais identidades produzem leituras específicas acerca do que são interesses nacionais. Exemplos empíricos interessante nesse caso são a construção da "identidade árabe", que levou vários países a estabelecerem alianças que pouco sentido tinham do ponto de vista das políticas de segurança (Blyth 2003); ou a análise de Acharya (2004) acerca do impacto de normas transnacionais sobre a Associação de Nações do Sudeste Asiático (ASEAN), em que se mostra o modo pelo qual atores nacionais reconstroem ideias internacionais, preservando sua identidade; a análise de Heclo (1974), por sua vez, revela os diferentes interesses que grupos de pressão similares defendem em relação às políticas sociais em países distintos; ou, por fim, a análise de Gourevitch (1989) sobre como o keynesianismo redefiniu a percepção que fazendeiros e trabalhadores urbanos tinham de seus interesses, viabilizando a coalizão entre eles nos Estados Unidos e na Suécia (Gourevitch 1989).

III.2. Ideias como variáveis explicativas

Reconhecer a autonomia das ideias diante de interesses implica levá-las a sério. Levar ideias a sério significa, por sua vez, que elas modelam a ação de indivíduos e, por conseguinte, não são redutíveis a variáveis não ideacionais (Berman 1998; Mehta 2011; Jacobs 2015). Segundo os autores do ID, incluir ideias como variável explicativa na análise de políticas públicas permite enten- 
der porque as coisas ocorreram da maneira como ocorreram e, assim, superar a preocupação com os limites negativos que constrangimentos institucionais e contextuais impõem à ação. Como menciona Kingdon (2014), não é somente o poder, a pressão e as estratégias de grupos que levam uma ideia a ser vitoriosa, mas também o seu conteúdo que, "longe de ser mera cortina de fumaça ou racionalização, é parte integral do processo decisório dentro e fora do governo". São vários os exemplos de autores que realizam esse movimento teórico: Heclo (1974), em análise sobre o impacto da teoria econômica keynesiana na redefinição da política de desemprego na Grã-Bretanha e na Suécia; Kingdon (2014), em exame dos efeitos de grandes parâmetros normativos sobre o processo de transformação de determinadas "condições" em "problemas" na política de transporte americana; Berman (1998) observa que sem referência às "crenças programáticas" do Partido Social Democrata Alemão e do Partido Social Democrata Sueco não é possível entender como e por que essas duas agremiações, submetidas a constrangimentos estruturais muito semelhantes, responderam de forma tão distinta aos desafios do início do século XX; Cox (2004; 2001), em tese sobre as continuidades e mudanças nas políticas de bem-estar social em países nórdicos e na Alemanha; Wuthnow (1989), em sua análise sobre os impactos ideacionais duradouros da Reforma, do Iluminismo e do Socialismo nas sociedades europeias e Kindleberger (1975), em estudo sobre os determinantes ideológicos da ascensão do livre comércio na Europa do século XIX (Kindleberger 1975). Se, como diz Prost (2003), as maneiras de falar não são inocentes, mas ocultam tabus e preconceitos e revelam estruturas mentais, então cabe perguntar "em que medida as políticas são determinadas pelo vocabulário que permite formulá-las" (Prost 2003, p.296).

III.3. Atores como seres reflexivos

O ID também aceita que instituições são constrangimentos que estabelecem regras e regularidades. No entanto, ao focar nas ideias de atores concretos, essa corrente teórica "infunde" nessas estruturas a ação. Instituições são "estruturas e constructos ideacionais internos" de agentes sencientes (Schmidt 2010). Nesse sentido, o ID introduz no debate o conceito de discurso, que descreve essencialmente a dinâmica dos argumentos em interação como forma de convencer os outros. Schmidt aponta ainda para a existência de diferentes instâncias discursivas. Na "esfera coordenadora", em que as elites precisam produzir decisões negociadas, produz-se um tipo de "discurso coordenativo"; na "esfera comunicativa", utilizam-se "discursos comunicativos" adequados à interação com o público mais amplo. O ID apresenta, assim, a grande vantagem de não pensar a política apenas em termos de relações de poder e pressão, mas também como interação discursiva produtora de aprendizados, como sugerido por Heclo (1974), e a serviço da construção de "comunidades imaginadas" (Anderson 1991; P. Hall 1993).

Mais uma vez, não se trata de negar o óbvio, isto é, recusar que a política é amplamente marcada por relações de poder entre grupos de pressão que querem ver seus interesses contemplados nas políticas públicas (Kangas et al., 2014), mas de mostrar que as trocas discursivas, as justificativas intelectuais (Crawford 2006) e o aprendizado são mais frequentes na vida política do que supõe alguns teóricos (Pierson 2000) ${ }^{4}$. Segundo Heclo (Heclo 1974), relações de poder entre grupos pode ser o "gatilho" ou o "estímulo" para se fazer algo, mas não explica porque dado curso de ação concreto foi escolhido em detrimento de outros: o what to do depende muito do embate discursivo, de ideias legítimas e do aprendizado com políticas passadas ${ }^{5}$. 


\section{III.4. Indivíduos não intercambiáveis}

4 À pergunta "por que obedecer?", aquele que exerce o poder permite-se responder apenas "porque sim", pois, nesse caso, a obediência é obtida pela simples ameaça de privações severas. No caso da autoridade, aquele que manda está obrigado a apresentar boas razões para obter obediência, boas razões que estão sempre intimamente articuladas com ideias socialmente aceitas (Friedrich 1974, p.52-60).

${ }^{5}$ No processo decisório pode haver "aprendizado positivo" (saber o que fazer), "aprendizado negativo" (saber o que não fazer) e "não-aprendizado" (incapacidade de promover adaptações a partir das experiências passadas). Cf. Heclo (1974)

${ }^{6}$ J. Hall (1993) propõe, nesse sentido, correção à proposição de Max Weber. Para ele, não basta pensar ideias como trilhos sobre os quais correm as ações, mas também naqueles que "instalam os trilhos" (tracklayers): "os momentos em que o poder da ideologia é mais autônomo têm sido aqueles em que intelectuais serviram como (...) tracklayers" (J. Hall 1993).

\section{III.5. Mudanças políticas}

\footnotetext{
${ }^{7}$ Cox (2004) tem razão ao dizer que limitar o estudo do impacto das ideias a situações de mudança pode ser frustrante metodologicamente por pressupor alterações
}

A recusa da definição objetivista de interesses (derivados automaticamente de posições institucionais ou de axiomas acerca da natureza humana), conjugada com o lugar de destaque dado tanto a crenças e práticas discursivas como também ao caráter sócio-histórico dos atores, resulta diretamente em dizer que os indivíduos não são intercambiáveis (Hay 2011). Considerar o impacto das ideias significa reconhecer a idiossincrasia ideacional dos atores políticos e sociais e, por consequência, aceitar que indivíduos diferentes agirão de maneira distinta em contextos institucionais similares (Walker 1990). Ou seja, o resultado político não depende apenas das posições de poder dos atores institucionais, mas em grande parte também de como eles, a partir de suas crenças, interpretam e percebem seus interesses. Como crenças são históricas e contextuais, é pouco provável que instituições semelhantes no seu desenho morfológico resultem em comportamentos idênticos. Daí a importância de se focar em policy entrepreneurs (Kingdon 2014), political entrepreneurs (Hogan \& Feeney 2012) ou carriers (Berman 1998). Segundo Cox (2001), a "abordagem social-construtivista pode explicar padrões dissimilares de reforma em países em que se esperava mudanças similares e dependentes de trajetória”. Enfim, o construtivismo não enfatiza apenas ideias, mas também agentes que lutam por ideias, evidenciando o papel central dos empreendedores políticos, corretamente apontado por Cox (2001) como complemento teórico do construtivismo. Se ideias são socialmente construídas, então é preciso encontrar seus construtores, que, na perspectiva de J. Hall (1993), são construtores da própria sociedade ${ }^{6}$.

Estudos comparativos feitos por autores vinculados a essa perspectiva mostram como atores portadores de ideias diferentes produzem resultados distintos apesar de inseridos em situações institucionais similares (Heclo 1974; Cox 2001). Ademais, a percepção de que agentes específicos com ideias específicas podem fazer a diferença, permite avanços nas teorias acerca da autonomia do Estado. Por exemplo, Goldstein (1988) lembra que agentes estatais não decidem apenas por pressão de grupos sociais externos ou por pressão de outros Estados nacionais, mas em função também de interesses e crenças próprios; P. Hall (1986) revela como, no caso de Thatcher, a forte adesão ao monetarismo foi importante para resistir à pressão de vários grupos de interesse, aumentando assim a autonomia dos decisores perante esses grupos.

Por fim, levar ideias a sério permitiria “endogeneizar" a explicação sobre mudança política, em vez de pensá-la a partir do impacto de variáveis exógenas. Ideias, sobretudo quando usadas na dinâmica de interações discursivas, constituem-se em "variável mediadora" entre mudanças estruturais (na economia, por exemplo) e mudanças institucionais na política (Skogstad 1998; Blyth 2001; 2003; Lieberman 2002; Béland 2005; Schmidt 2010). Tal proposição implica que mudanças de ideias, mesmo na ausência de grandes crises exógenas, podem produzir mudanças nas políticas, modelando agendas, definindo problemas públicos, impactando o conteúdo de propostas sobre reforma política e construindo "imperativos de reforma" (Blyth 2003, pp.702-712).

No entanto, a preocupação com a mudança política não impede os adeptos da virada ideacional de considerar a estabilidade política. Preocupados com mudanças e rotinas Cox $(2004)^{7}$, alguns autores procuram elaborar definições mais complexas sobre ordem política. Lieberman (2002), por exemplo, explica mudanças de padrões sem recorrer a uma variável exógena. $\mathrm{O}$ autor considera que a ordem política não é internamente coerente, pois há múltiplas ordens políticas, e afirma que jogos políticos estão situados em uma variedade de 
dramáticas na vida política. É preciso analisar também o impacto das ideias no funcionamento rotineiro da vida. Daí dedicar-se ao estudo da stickness do modelo escandinavo e a lógica de path nas políticas públicas. dependence que ela instaura

padrões institucionais e ideológicos ordenados, com origens, histórias e lógicas próprias. Assim, a ordem política é, ao mesmo tempo, fonte de reprodução e local de contradição e mudança. "As ordens ideológicas e institucionais em qualquer tempo ou lugar determinado dificilmente estão conectadas umas com as outras de modo coerente ou funcional (...). É na fricção entre as ordens que podemos mais prontamente encontrar as sementes da mudança dentro da política em dado momento" (Lieberman 2002). Nesse sentido, nem sempre fenômenos políticos são inteiramente explicáveis em termos de path dependence, pois construções argumentativas podem produzir path shaping que altera o funcionamento da lógica institucional sem que ocorra qualquer mudança profunda prévia na morfologia das instituições. Assim, ideias podem ser vistas como variáveis independentes que causam reformas e mudanças. Ao mesmo tempo, porém, a path dependence não tem apenas significado institucional, mas também ideacional, ou seja, ideias antigas afetam as chances de sucesso de novas ideias (Cox 2001; Hay 2011; Pierson 2000).

Muitos dos trabalhos que analisam as políticas de bem-estar social do norte europeu (Larsen \& Andersen 2009; Heclo 1974; Blyth 2001; Cox 2004; 2001); as políticas agrícolas na Comunidade Europeia e nos Estados Unidos (Skogstad 1998); as políticas de redução da pobreza da Argentina na década de 1990 (Panizza \& Miorelli 2013); a gestão de crises econômicas nos Estados Unidos, na Suécia e na Irlanda (Hogan \& O'Rourke 2014; Hogan \& Feeney 2012); ou a evolução da política sobre direitos civis nos Estados Unidos (Lieberman 2002) enfatizam o papel de ideias na permanência e nas mudanças das políticas públicas analisadas.

É claro que a radicalização da importância das ideias pode conduzir com alguma facilidade a posições estritamente idealistas. Hay (2001), ao recusar de forma contundente a existência de interesses objetivos, parece ser forte candidato à comissão desse pecado. A ideia de que não existem interesses objetivos $a$ priori parece essencialmente correta, mas simplesmente descartar posições do mundo objetivo, como tende a fazer o autor, não nos parece o caminho adequado. O mais correto seria mostrar como "ideias" se articulam com "situações de interesses" na definição da conduta. Esse parece ser o caminho também sugerido por diversos autores. P. Hall (1993), por exemplo, insiste que é mais frutífero pensar de maneira equilibrada a relação entre ideias e circunstâncias de modo a evitar posições idealistas pouco críveis. Wuthnow (1989) refere-se ao "problema da articulação", isto é, à interação entre a autonomia das ideias e o ambiente social em que prosperam. Enfim, trata-se da recusa ao mesmo tempo do objetivismo e do pós-modernismo e de conjugar condicionantes sócioinstitucionais e ideacionais na configuração das relações de poder e da política (Béland 2010; Lieberman 2002).

Por fim, para que o leitor possa ter uma visão panorâmica e comparativa das diferenças entre o institucionalismo de escolha racional (IER), o institucionalismo histórico (IH), o institucionalismo sociológico (IS) e o institucionalismo discursivo (ID), apresentamos suas principais características no Quadro 1.

\section{O que são ideias}

Vimos acima como que os adeptos de uma perspectiva discursiva defendem a capacidade explicativa das ideias. Mas, afinal, como essa literatura define ideias? Aqui entramos em terreno pantanoso com definições amplas e, ao mesmo tempo, triviais, como, por exemplo, "perspectivas intelectuais" (Goldstein 1988), "visões sobre o funcionamento do mundo" (Hogan \& O'Rourke 2014) ou "descrições do mundo" (Béland 2010). Há, no entanto, diversas tentativas de produzir definições mais específicas e operacionais que buscam produzir "tipologias de ideias", hierarquizá-las e diferenciá-las quanto ao tipo 
Quadro 1 - Características das teorias institucionalistas

\begin{tabular}{lllll}
\hline & $\begin{array}{l}\text { Institucionalismo de } \\
\text { Escolha Racional } \\
\text { (IER) }\end{array}$ & $\begin{array}{l}\text { Institucionalismo } \\
\text { Histórico (IH) }\end{array}$ & $\begin{array}{l}\text { Institucionalismo } \\
\text { Sociológico (IS) }\end{array}$ & $\begin{array}{l}\text { Institucionalismo } \\
\text { Discursivo ID }\end{array}$ \\
\hline Objeto & $\begin{array}{l}\text { Comportamento } \\
\text { racional e interesses }\end{array}$ & Padrões históricos & Normas culturais & Ideias e discursos \\
Lógica da explicação & $\begin{array}{l}\text { Ação estratégica } \\
\text { maximizadora }\end{array}$ & $\begin{array}{l}\text { Dependência de } \\
\text { trajetória }\end{array}$ & $\begin{array}{l}\text { Comportamento } \\
\text { orientado por normas }\end{array}$ & Interação discursiva \\
Perigos da explicação & $\begin{array}{l}\text { Determinismo } \\
\text { econômico }\end{array}$ & Determinismo histórico & Determinismo cultural & Idealismo \\
$\begin{array}{l}\text { Capacidade de explicar } \\
\text { mudanças políticas }\end{array}$ & $\begin{array}{l}\text { Baixa: continuidade e } \\
\text { preferências fixas }\end{array}$ & $\begin{array}{l}\text { Baixa: continuidade e } \\
\text { dependência de } \\
\text { trajetória }\end{array}$ & $\begin{array}{l}\text { Baixa: continuidade e } \\
\text { estabilidade normativa }\end{array}$ & $\begin{array}{l}\text { Alta: interação } \\
\text { discursiva e mudança } \\
\text { nos padrões decisórios }\end{array}$ \\
\hline
\end{tabular}

Fonte: Os autores, a partir de quadro elaborado por Schmidt (2011, p.49).

${ }^{8}$ Ver, por exemplo, Schmidt \& Thatcher (2013) e Schmidt (2013). de impacto que poderiam gerar. O objetivo de tais investidas é distinguir dimensões ideacionais mais estruturantes e abrangentes de dimensões ideacionais mais instrumentais e específicas ${ }^{8}$.

No primeiro caso, os autores se referem àquilo que Searle (2002) chamou de background, isto é, um tipo de "saber prático", de "práticas culturais locais", de "suposições e pressuposições pré-intencionais". Segundo esse autor, o conceito de backgorund permite pensar como a formulação de intenções está conectada ao contexto cultural que fornece ao indivíduo categorias a partir das quais ele elege objetivos a serem perseguidos. Como se percebe, é algo bem próximo do que Pierre Bourdieu chamou de habitus, isto é, um conjunto de pré-disposições duráveis e infraconscientes que afetam a conduta dos atores (Bourdieu 1989; Schmidt 2010); ou do que Wuthnow identificou como "campo discursivo", formado pelas "categorias fundamentais nas quais o pensamento pode ocorrer" e que "define os limites da discussão e o elenco de problemas que podem ser abordados" (Wuthnow 1989). Na literatura sobre a virada ideacional esse conceito aparece por meio de termos como "visões de mundo" (Goldstein \& Keohane 1993; Berman 1998; Schmidt \& Thatcher 2013; Schmidt 2013), "repertórios ideológicos" (Béland 2005; 2009b), "filosofias públicas" (Mehta 2011), "ideias filosóficas" (Schmidt 2014), "estruturas normativas" (Campbell 2002), "crenças filosóficas" (George 1979), "crenças sociais consensuais" (Jacobsen 1995) ou "redes culturais de significado" (Yee 1996). Essas "visões de mundo" funcionariam como "sistemas de crenças" (Converse 1964), internamente coerentes, que definiriam estratégias diante de problemas concretos, condizentes com grandes orientações normativas. Kingdon (2014), analisando o caso dos Estados Unidos, ilustra essa proposição ao afirmar que é sempre difícil nesse país levar adiante propostas que defendam programas públicos de saúde, pois há forte resistência cultural advinda do americano médio, que valoriza o esforço individual e tem forte suspeição do Estado.

O problema fundamental aqui é como, metodologicamente, vincular essas visões de mundo a decisões em áreas específicas. Mesmo que consideremos essas visões de mundo como "sistemas de crenças" internamente articulados e coerentes, a abrangência de seus parâmetros normativos possibilita a convivência de orientações incongruentes diante de assuntos muito específicos e torna difícil estabelecer relações inequívocas entre valores culturais e opções de políticas públicas concretas (Berman 1998). Não é por outra razão que esse nível de análise é, de longe, o mais ausente da literatura empiricamente orientada ao estudo das ideias ${ }^{9}$.
${ }^{9}$ Walker (1990, p.142) 
observa que, a partir de certo momento, o conceito de "sistema de crenças" foi abandonado por se mostrar demasiado rígido, incapaz de captar a ambiguidade das crenças. Seguiu-se, então, uma substituição da versão "sistema de crenças" do código operacional por uma "teoria da consistência cognitiva”. Cf. Walker (1990).

${ }^{10}$ Essas ideias aparecem resumidas também em Perissinotto \& Szwako, 2017.

${ }^{11}$ Para distinções semelhantes ver Rueschemeyer (2006) George (1979) e Walker (1990).
Também não é por outra razão que, em parte dessa literatura, há esforços sistemáticos para pensar dimensões ideacionais mais operacionais para a pesquisa empírica (Rueschemeyer 2006). Um modo de avançar nessa questão é pensar ideias a partir de universos mais restritos, isto é, a partir de áreas decisórias específicas. O objetivo não seria tanto saber qual é o pano de fundo cultural de uma dada sociedade, mas sim identificar parâmetros normativos no interior de uma policy community para, então, pesquisar como estes afetam a escolha de problemas, seu enquadramento e a formulação de soluções. Mais uma vez, as formulações conceituais são inúmeras. Talvez a mais conhecida e influente seja a de "paradigma", formulada por P. Hall (1993). No caso específico da política econômica, paradigmas seriam "ideologias econômicas" (P. Hall 1993), nunca totalmente articuladas, que priorizam determinados problemas (por exemplo, o lugar central do pleno emprego no paradigma keynesiano e o lugar central da inflação no paradigma monetarista) e determinadas soluções (políticas de manejo da demanda agregada em um caso, políticas de restrição fiscal e monetária, no outro). Mudanças em paradigmas, portanto, implicam mudanças qualitativas nas políticas públicas - também chamadas por P. Hall (1993) como mudanças de terceira ordem. O objeto de análise torna-se, assim, muito mais circunscrito, cabendo ao analista avaliar as agências decisórias específicas das políticas, os atores políticos e sociais que formam a community policy, os embates políticos e os intelectuais que a caracterizam, a comunidade de especialistas e as coalizões políticas que a elas se vinculam. Muitos outros autores formulam conceitos similares. Por exemplo: "policy ideas" (Béland 2005; Schmidt 2014); “crenças causais" (Goldstein 1993; Goldstein \& Keohane 1993), "paradigmas cognitivos" (Campbell 2002); "crenças programáticas" (Berman 1998; Hansen \& King 2001), “crenças instrumentais” (George 1979) ou "ideias programáticas” (Schmidt 2014).

Avaliamos, porém, que a melhor contribuição nesse sentido se encontra em um texto de John Campbel, de $1998^{10}$. Segundo o autor, é preciso pensar a diferenciação de ideias a partir do cruzamento entre dois tipos de constrangimentos e duas dimensões de operação, gerando quatro quadrantes: programas, enquadramento, paradigmas e sentimentos públicos (Quadro 2).

A dimensão do background descreve os pressupostos subjacentes, naturalizados e infraconscientes que habitam o pano de fundo dos debates políticos; a dimensão do foreground descreve as ideias usadas e articuladas estrategicamente pelas elites políticas. Essas duas dimensões, portanto, casam os pressupostos do IS e do ID. Constrangimentos normativos operam quando ideias se constituem em valores e atitudes que diferenciam o certo do errado e limitam a ação, inviabilizando formas alternativas de pensar e agir; constrangimentos cognitivos operam quando conceitos culturalmente dados são usados para produzir determinadas soluções de problemas específicos e excluir outras ${ }^{11}$. Ou seja, é quando ideias definem relações de causa e efeito (Campbell 1998).

Assim, paradigmas e programas são constrangimentos cognitivos que definem maneiras aceitas de resolver problemas, mas que operam em dimensões

Quadro 2 - Dimensões e constrangimentos dos discursos

\begin{tabular}{lcc}
\hline Constrangimentos & \multicolumn{2}{c}{ Dimensões } \\
\cline { 2 - 3 } & $\begin{array}{c}\text { Conceitos de primeiro plano } \\
\text { (foreground concepts })\end{array}$ & $\begin{array}{c}\text { Pressupostos de fundo } \\
\text { (background assumptions) }\end{array}$ \\
\hline Nível cognitivo & Programas & Paradigmas \\
Nível normativo & Enquadramento & Sentimentos públicos \\
\hline
\end{tabular}

Fonte: Campbel (1998). 
distintas. No caso de paradigmas, pressupostos de fundo, internalizados pelos agentes em processos de socialização de longa duração, limitam o elenco de soluções que as elites tendem a perceber como adequadas; no caso dos programas, trata-se de prescrições precisas de políticas públicas mobilizadas estrategicamente na luta política e que, ancoradas em paradigmas, facilitam a ação entre elites para definir como resolver um problema específico de política pública (Campbell 1998).

Os sentimentos públicos e o enquadramento são, por sua vez, constrangimentos normativos que impõem distinções entre o certo e o errado, e que também operam em dimensões distintas. Sentimentos públicos são pressupostos normativos de fundo, internalizados, que legitimam ou deslegitimam, que autorizam ou desautorizam, enfim, que tornam determinados temas aceitáveis ou inaceitáveis ao público. Fornecem, assim, a base da legitimidade política. Enquadramento refere-se a um modo de, na luta política, apresentar estrategicamente certos programas e soluções com vistas a torná-los compatíveis com o sentimento público dominante e, assim, legitimá-los perante a população. A luta política é uma luta permanente de enquadramento e contraenquadramento (Campbell 1998; Hay 1996).

É claro que esses constrangimentos e dimensões estão interligados. Como diz Campbel (1998), "paradigmas e sentimentos públicos são conceitos de segunda ordem na medida em que se constituem em ideias subjacentes sobre as quais os conceitos de primeira ordem, isto é, programas e enquadramentos, baseiam-se respectivamente". De qualquer forma, parece-nos que a sistematização de Campbel (1998) deixa o problema do impacto das ideias em políticas públicas muito mais circunscrito e, o mais importante, permite estabelecer uma conexão mais precisa entre tipo de ideias e natureza do impacto que produzem.

\section{Quando e como ideias impactam}

A literatura da virada ideacional enfatizou a importância de se levar em consideração as ideias por si mesmas, analisar aquilo que os discursos proscrevem e prescrevem, a fim de produzir um entendimento pleno dos fenômenos políticos. Para tanto, como vimos até aqui, os pesquisadores precisaram produzir definições mais específicas acerca do que entendem por "ideias". Precisamos agora abordar como, a fim de evitar os perigos do idealismo a que já nos referimos, os estudiosos do tema se dedicaram a especificar as condições e circunstâncias em que as ideias afetam o processo político. Ou seja, é preciso analisar quando as ideias impactam para, em seguida, discutirmos como impactam.

\section{V.1. Quando ideias impactam}

Ao se perguntarem quando ideias impactam, autores filiados a essa literatura estão preocupados em delimitar as "circunstâncias" (P. Hall 1993) que viabilizam a efetividade ideacional. Trata-se de saber quais condições permitem uma ideia se sobrepor a outras e se consolidar como padrão ideológico dominante. A partir da literatura, dividimos tais condições em três tipos: condições político-institucionais, condições de incerteza e condições de path dependence.

A análise paradigmática que enfatiza condições político-institucionais como potencializadoras do impacto de ideias foi elaborada por P. Hall (1989). Na verdade, já em 1986, em seu livro sobre política econômica na Grã-Bretanha e na França, o autor enfatizava a importância de fatores institucionais para a viabilização de determinadas ideias econômicas. P. Hall (1986) mostra como o padrão de política econômica, industrial e de renda, encontrado na Alemanha, na França e na Grã-Bretanha, correlaciona-se com o padrão organizacional do 
12 Elementos-chave nesse processo são, além dos grupos governamentais e extragovernamentais, os policy entrepreneurs, indivíduos dispostos a dispender recursos, tempo e energia na defesa de uma ideia (Kingdon 2014).
13 A literatura se refere a essas situações como knightian uncertainty (do trabalho de Frank Knight, Risk, Uncertainty and Profit), situações em que os agentes não têm clareza dos seus interesses. Diferem de situações de risco, em que os agentes sabem quais são seus interesses, mas não como realizá-los.
Estado e também com o tipo de relação entre Estado, capital e trabalho (P. Hall 1986). Em 1989, P. Hall (1989) complementa sua análise ao afirmar que duas características definem a capacidade de ideias impactarem em políticas econômicas: a força das ideias em si (isto é, sua coerência, seu estatuto teórico etc.) e as circunstâncias externas (isto é, conexão com os problemas reais, com ideias prévias e com decisores). Quanto a este ponto, P. Hall (1989) identifica três condições que viabilizam determinadas ideias: (1) viabilidade econômica (no caso de ideias econômicas), quando as ideias apresentadas dependem do reconhecimento das teorias existentes, da natureza da economia nacional e dos constrangimentos internacionais; (2) viabilidade administrativa, quando dependem do viés e poder relativo das agências responsáveis pela implementação da política econômica; (3) viabilidade política, quando dependem dos objetivos do partido dominante, dos interesses dos parceiros potenciais e da relação com associações coletivas com interesses similares (P. Hall 1989). Se uma ideia não contemplar essas três condições simultaneamente, terá poucas chances de vingar.

Outros autores, de forma menos sistematizada, antes e após P. Hall (1989), apontaram para condições similares. Por exemplo, Kingdon (2014, pp.131-144) já se referia à necessidade de uma ideia possuir viabilidade técnica, institucional e política para ser aceita, prosperar e produzir aquilo que ele chamava de bandwagon effect, isto é, adesão de diversos agentes políticos dispostos a defendê-la ${ }^{12}$; Gourevitch (1989) apontou para a importância das coalizões políticas, das instituições e do contexto internacional para a viabilização de ideias. Mais recentemente, Campbell (1998), Béland (2005), Goldstein (1993), Skogstad (1998), C. Parsons (2000), entre outros, também enfatizaram condições similares na viabilização de impactos ideacionais: a recepção das ideias por instituições estratégicas, sua defesa por atores políticos e sociais dotados de recursos de poder e a sua força teórica. Como afirmam Goldstein (1993, p.21) e Hogan \& O'Rourke (2014, p.3), o fato de novas ideias estarem disponíveis não explica porque são aceitas pelas elites, pois a receptividade depende da sua forma, do status dos seus defensores e do apoio em altas esferas administrativas.

A análise mais conhecida sobre condições de incerteza no processo de viabilização de determinadas ideias é de Goldstein \& Keohane (1993). Para os autores, existem duas situações em que recorrer a uma ideia é fundamental para solucionar problemas de escolhas. A primeira delas diz respeito a condições de absoluta incerteza sobre o que fazer ${ }^{13}$. Como observam, em situações de plena institucionalização e rotina nos procedimentos decisórios, ideias novas têm poucas chances de avançarem. Mas quando situações absolutamente novas se configuram e os atores não têm como escolher o caminho a seguir por total falta de informação, a saída é usar ideias como road maps (Goldstein \& Keohane 1993; Halpern 1993; Blyth 2002). Há situações de incerteza menos dramáticas, quando, por exemplo, os atores conseguem visualizar diversos pontos de equilíbrio que representam "melhoras paretianas para todos", mas não têm critérios objetivos de escolha. Enquanto no primeiro caso não há leque de escolhas, no segundo este existe, mas não se sabe exatamente qual caminho seguir. Nas duas situações, os atores afirmam que ideias funcionam como focal points ao viabilizarem a formação de coalizões políticas (Goldstein 1993, pp.17-18).

O sucesso de ideias em momentos de incerteza depende de suas qualidades ideacionais intrínsecas. Segundo Béland \& Cox (2016) e Cox \& Béland (2013), a valência de uma ideia reforça sua posição política e seu potencial impacto sobre relações de poder, pois sua ampla aceitação ajuda a garantir apoio político. Ideias polissêmicas, por sua vez, auxiliam em coalizões porque definições abrangentes permitem atores criativos "esticá-las" a fim de legitimar novas propostas políticas. Em pesquisa experimental sobre assistência social na Fin- 
lândia, Kangas et al. (2014) examinou empiricamente tal proposição. Ao testar como ideias concorrentes atuam sobre a opinião pública em momentos de incerteza, o autor revela que níveis de abstração e ambivalência de uma ideia estão diretamente ligados à sua eficácia.

Por fim, há analistas que enfatizam a path dependence ideacional como condição fundamental para viabilizar o impacto das ideias. Nesse caso, Heclo (1974) é o autor mais significativo. Para ele, um dos aspectos mais importantes do ambiente de uma política pública, mas com mais frequência negligenciado, é a própria política herdada (Heclo 1974). Em situações de incerteza, decisores sempre olham para o que foi feito no passado. Assim, a institucionalização de políticas passadas tende a afetar fortemente o que será decidido no futuro (Goldstein 1993; Goldstein 1988; Halpern 1993). Por exemplo, o início do seguro desemprego na Grã-Bretanha e na Suécia sofreu pouco interferência das mudanças partidárias, da competição eleitoral ou da pressão dos grupos de interesse, mas foi fortemente influenciado por políticas passadas, sobretudo por aquelas que assumiram a forma de "lei dos pobres". A tese também se repete na análise de pensões, quando o autor afirma que "em ambos os países, a herança de políticas passadas era em si mesma a força vital que modelou as alternativas percebidas e as políticas adotadas" (Heclo 1974). O autor observa ainda que diferenças na sequência do desenvolvimento dessas políticas criaram forças contextuais que modelaram as decisões nessa área nos países analisados.

Outros autores também enfatizam o fato de que ideias terão mais chances de impacto se forem alinhadas com ideias anteriores vigentes em dado contexto histórico. É o caso, por exemplo, do desenvolvimentismo e o terreno ideologicamente fértil por ele encontrado no Brasil, diferentemente da Argentina (Sikkink 1991). Situação similar é encontrada nos países da Associação de Nações do Sudeste Asiático (ASEAN), que aceitaram normas internacionais ao reconstruí-las tendo em vista crenças e instituições locais pré-existentes (Acharya 2004). Também é o caso da stickness do modelo escandinavo de welfare state, centrado nos princípios de universalismo, solidariedade e desmercantilização, que se tornou ponto de partida para elaboração de qualquer política social alternativa. Nos exemplos mencionados, predomina, assim, o comportamento orientado pela "lógica de adequação", restringindo o elenco de alternativas possíveis (Cox 2004). Em resumo, como dizia Kingdon (2014), em processos decisórios raramente surge algo totalmente novo.

V.2. Como ideias impactam

Vimos acima algumas condições que potencializam o impacto das ideias. Mas, uma vez presente tais condições, como ideias impactariam o resultado de políticas públicas? As respostas a essa questão tendem a enfatizar os aspectos ideacionais propriamente ditos e podem ser mais ou menos abrangentes.

Quando são mais abrangentes, os autores afirmam que a cultura ou as ideias fornecem significados ou geram regras para a ação social (P. Hall 1993, p.43). Interessa, porém, ver como a literatura pensa o tipo de impacto que as ideias podem causar em áreas decisórias específicas. Desse ponto de vista, valendo-se das contribuições de Kingdon (2014), a literatura pensa o impacto de ideias a partir de três dimensões: na definição de problemas (problem stream), na formulação de políticas e alternativas (policy stream) e na mobilização política (political stream) (Béland 2009a; Jaiani \& Whitford 2011). Vejamos cada um deles a seguir.

No que diz respeito ao primeiro ponto, trata-se de afirmar que ideias vigentes em determinada área de política pública afeta o processo de conversão de uma "condição" em "problema" e o seu enquadramento. Como observa 
${ }^{14}$ Para o impacto do keynesianismo na política de desemprego ver Heclo (1974, pp.66-67 e pp.100-117). ${ }_{15}$ Para exemplificar as diversas dimensões das ideias, Walsh (2000) diz que o thacherismo é uma "ideologia", um "paradigma cognitivo" ou uma "estrutura normativa", enfim, um "paradigma" de política econômica, enquanto que o monetarismo é uma "ideia programática" ancorada naquele paradigma. Cf. Walsh (2000) e Campbel (1998).

${ }^{16}$ Policy communities se aproxima do conceito de think tanks, definido como organizações independentes envolvidas na investigação multidisciplinar. Para influenciar políticas públicas, think tanks lançam mão de processos de influência similares aos das policy communities. Sobre este tema, ver os trabalhos de Rich (2005b; 2005a), Desai (1994) e James (1993).
Kingdon (2014), uma condição (por exemplo, a pobreza) nunca é naturalmente elevada ao status de problema público a ser alvo de política governamental. Várias condições objetivas (por exemplo, catástrofes, queda abrupta em determinado índice) podem contribuir para isso, mas são de fundamental importância também os "valores" dos participantes que atuam no processo decisório. Além disso, um problema precisa ser enquadrado, isto é, precisa ser apresentado ao público utilizando-se certas "categorias" que as elites decisórias avaliem ser de recepção mais positiva. Esse é um exemplo de como "paradigmas" e "enquadramento" se constituem em dimensões ideacionais diferentes a operarem em momentos distintos do processo decisório (Kingdon 2014; Béland 2009b). Paradigmas são parâmetros gerais que induzem seus portadores a lerem uma condição como problema, já categorias são formas de "enquadrar" uma condição transformada em problema e apresentá-lo sob formulação aceitável ao sentimento público dominante. Dois atores com valores diferentes, um keynesiano e outro cristão, por exemplo, podem perceber a condição de desemprego como problema, mas tenderiam a enquadrá-lo de maneiras diferentes: o keynesiano trataria o desemprego como resultado estrutural de ciclos econômicos e problema a ser combatido com políticas ativas de gastos públicos ${ }^{14}$; o cristão, por sua vez, tenderia a vê-lo como um drama humano a ser abordado pela via da filantropia. Nesse sentido, "pleno emprego" e "filantropia" seriam categorias de enquadramento que operam dentro de parâmetros normativos mais gerais ${ }^{15}$.

Ideias impactam também na seleção de soluções para problemas. Ou seja, uma vez que uma condição é transformada em problema e seu enquadramento é dado sob determinada perspectiva, o que explica a escolha de uma solução em detrimento de outras? Segundo Kingdon (2014), nesse momento do processo decisório, dois tipos de atores políticos são centrais: as policy communities, como grupos de especialistas, fora e dentro do governo, que atuam em área específicas de política pública ${ }^{16}$, e os policy entrepreneurs, agentes que investem seus recursos (tempo, energia, reputação, dinheiro) para influenciar o processo decisório. Nos dois casos, além de fatores objetivos (interesses, recompensas, pressão de grupos de interesse), especialistas e empreendedores têm nos valores e ideias elementos condicionantes de suas ações. Particularmente no caso dos especialistas, paradigmas dominantes de áreas científicas afins com a política pública em questão são de grande importância (Kingdon 2014). É nesse momento do processo decisório que ideias, usadas como "crenças causais", "ideias pragmáticas" (Goldstein \& Keohane 1993; Campbell 2002) ou "crenças programáticas" (Hansen \& King 2001), alimentadas pela expertise (Seabrooke \& Wigan 2016), redefinem interesses, prescrevem soluções para problemas e geram programas de políticas públicas específicos (Ikenberry 1993). Essa dinâmica é também observada em escala global. Seabrooke \& Wigan (2016), analisando o caso da política fiscal global, argumentam que ideias são alimentadas pela expertise e se constituem como arena de disputa na definição de grandes soluções para os problemas de gastos e arrecadação dos principais países do mundo.

Por fim, ideias são importantes também na mobilização política cotidiana, pois para alguns autores é nesses espaços que reside a possibilidade de romper certos padrões institucionalizados. Como lembra Kingdon (2014), a luta política constitui, ao lado da definição de problemas e alternativas, outro fluxo essencial do processo decisório. Ideias, para vingar, precisam enunciar problemas, formular soluções e, por fim, virar proposta política, o que demanda, entre outras coisas, convencer vários atores, formar coalizões de apoio e, para tanto, contar com o empenho de political entreprenuers (Hogan \& Feeney 2012). Aqui ideias podem ser utilizadas pelos political entreprenuers como "armas", isto é, como meio de estigmatizar formas antigas de encaminhar conflitos (Blyth 2001) ou como focal points, isto é, como instrumentos ideaci- 
17 A partir da sociologia de Goffman, Berger e Luckmann, Béland (2005) diz que o "enquadramentos da retórica" baseia-se em "conjuntos relativamente coerentes de símbolos culturais e representações políticas". Béland (2005, p.706). Segundo Hochschild, porém, "o estudo de como as ideias afetam as ações deve reservar um papel para a inovação, a criatividade, a inspiração e a liderança" (Hochschild 2006, p.294). onais para ajudar a produzir consenso e viabilizar a ação coletiva (Goldstein \& Keohane 1993). Para Béland \& Cox (2016) ideias formam coalitions magnets, definidas como a capacidade de alcançarem diversos indivíduos e grupos e serem usadas estrategicamente por policy entrepreneurs para enquadrar interesses, mobilizar apoiadores e construir coalizões.

Para alguns autores, é nos espaços da luta política cotidiana que reside a possibilidade de romper padrões institucionais. No entanto, segundo Schmidt (2010), a maior parte das teorias que incluem as ideias em seus modelos explicativos tendem a pensá-las em termos de "paradigmas". Ao fazê-lo, certamente contribuem para mostrar como ideias, pela via da institucionalização, produzem impactos de longa duração sobre políticas públicas, mesmo quando seus pioneiros já não estão mais à frente de instituições que criaram (Goldstein \& Keohane 1993; P. Hall 1989; Rueschemeyer 2006). Porém, a ênfase na institucionalização de ideias não permite pensar mudanças, incrementais ou não, de políticas públicas. A institucionalização funcionaria como uma espécie de "bloqueio cognitivo", gerando uma intelectual path dependence (Blyth 2001).

Para pensar mudanças de maneira sistemática é preciso analisar o "discurso", isto é, "o processo interativo de geração de ideias, deliberação e legitimação". Discurso, na definição de Schmidt (2010, p.15), “descreve não apenas o que é dito, ou ideias que compõem o conteúdo substantivo do discurso, mas também quem diz, para quem diz, onde diz e por que diz". Esse processo discursivo ocorre na "esfera coordenadora de políticas públicas" e na "esfera política comunicativa" e ajuda muito a explicar as mudanças institucionais. O discurso deve ser entendido como "troca de ideias", como embates em torno do enquadramento de ideias, isto é, "um processo de enquadramento e contraenquadramento". Para participar de interações discursivas, como vimos, os indivíduos devem possuir foreground discursive abilities. Esse conceito é essencial para explicar mudanças institucionais porque descreve a habilidade para “comunicar 'boas' ideias sobre políticas públicas por meio de discursos persuasivos, [o que] ajuda atores políticos a ganharem eleições e a dar a atores de políticas um mandato para implementar suas ideais" (Schmidt 2010, p.16). Os atores, nesse processo, perseguem seus objetivos de acordo com suas ideias, pensam e refletem sobre seus pensamentos, sobre suas ações, sobre suas interações e alteram seus pensamentos e ações. São atores sencientes, reflexivos e criativos. Por isso, em meio ao embate discursivo, novas ideias podem surgir, mesmo que não previstas pelos limites cognitivos e normativos dos paradigmas e visões de mundo dominantes (Schmidt 2010; 2013) ${ }^{17}$.

$\mathrm{Na}$ verdade, certas abordagens tributárias do institucionalismo discursivo permitiriam fugir da antinomia entre permanência e mudança. Esta seria, por exemplo, a vantagem do conceito de "resiliência", sistematizado por Schmidt \& Thatcher (2013). Esses autores mostram que o neoliberalismo, enquanto ideologia econômica, foi capaz de permanecer numa posição hegemônica dentro do embate discursivo no campo da política econômica exatamente porque se revelou flexível o suficiente para se adaptar aos novos desafios políticos colocados pelas ideologias concorrentes sem, contudo, abandonar suas proposições nucleares. Essa maleabilidade, segundo os autores, é inerente a essa ideologia econômica e sua falta de especificidade foi antes uma vantagem que um problema na luta política. Foi a resiliência do neoliberalismo que permitiu a sua continuidade, mesmo quando de suas receitas resultava apenas o fracasso econômico.

Como vimos, a literatura informa sobre as condições em que ideias impactam (político-institucionais, incerteza e path dependence) e como impactam (agendando e enquadrando problemas, definidos programas e viabilizando coalizões pela via do embate discursivo). Mas, cabe perguntar, como é possível 
verificar o impacto de ideias em processos decisórios? A questão é de natureza metodológica. A resposta a ela é o que veremos a seguir.

\section{Como verificar o impacto das ideias}

A literatura que discute a virada ideacional na análise de políticas públicas tem claras pretensões causais ao defender que decisões políticas são substantivamente afetadas por ideias (Hochschild 2006). Como em qualquer enunciado causal, exigem-se duas coisas: primeiro, negar a hipótese nula, a saber, que atores com interesses similares se comportarão de forma análoga mesmo que tenham ideias diferentes; segundo, sustentar o raciocínio contrafatual por meio de evidências mostrando que, caso aquelas ideias não estivessem presentes, os resultados políticos teriam sido diferentes (Goldstein \& Keohane 1993).

Antes de discutir os procedimentos utilizados para operacionalização de afirmações causais, é importante lembrar a observação feita por George (1979) e Rueschmeyer (2006). Segundo tais autores, ideias nunca agem sozinhas, o que equivale a dizer que sempre atuam juntas com outras variáveis contextuais. Apesar da centralidade na estrutura de crenças dos indivíduos, ideias, ou "códigos operacionais" na concepção de George (1979), nunca determinam unilateralmente as decisões. Decisões políticas são sensíveis a diversas outras variáveis, como considerações pessoais, política doméstica, interesses organizacionais, dentre outros ${ }^{18}$. Mas se isso é verdade, como provar que ideias de fato fazem a diferença? A nosso ver, a literatura tende a operar, nem sempre de maneira conjunta, com quatro procedimentos: (1) a identificação do conteúdo substantivo das ideias cujo impacto se propõe analisar; (2) o uso de desenho comparativo de pesquisa; (3) o procedimento da congruência e, por fim, (4) o process tracing. Vejamos cada um deles separadamente.

\section{VI.1. Descrição}

${ }^{18}$ Para George (1979, p.104), o código operacional "é mais importante na determinação de preferências [de um indivíduo] em relação a uma política pública (...) do que em determinar a opção que ele finalmente escolhe". Para Chartier é preciso recusar a ideia de uma relação causal linear entre uma ideia e uma prática em favor de uma "cultura política" geradora de "um conjunto de discursos concorrentes dentro de uma área unificada por referências idênticas" (Chartier 2003, pp. $42-43$.
Qualquer estudo que pretenda conferir às ideias lugar de destaque na explicação dos fenômenos políticos deve, antes de tudo, delimitar claramente o conteúdo das ideias que supostamente causam impacto nas decisões (Halpern 1993; Alston et al., 2016). Ao fazer isso, o analista identifica, no mesmo movimento, a singularidade da ideia em questão diante das demais configurações ideacionais. Portanto, como observa Béland (2005), uma das primeiras questões a serem respondidas pelo analista é saber se existem diferenças reais entre as ideias sustentadas por distintos grupos e se estas implicam em diferentes políticas. Para identificar a singularidade da ideia em questão é preciso analisar sua estrutura discursiva de modo a captar, como sugere Béland (2009b), os rhetorical frames a partir dos quais uma ideia enquadra problemas de políticas públicas. Há diversos métodos que permitem identificar essas estruturas discursivas (Mohr 1998; Wilkerson et al., 2015; Kangas et al., 2014).

Vários autores adotam e/ou iniciam suas análises a partir desse procedimento (Mandelkern \& Shalev 2010; Dobbin 2004; Bleich 2003; Skogstad 1998; Béland \& Cox 2016; Hansen \& King 2001). P. Hall (1989), por exemplo, procura definir o keynesianismo como política de gerenciamento anticíclico da demanda agregada, o que implicaria aceitar a intervenção governamental na economia e ter uma visão oposta ao monetarismo sobre o papel da política fiscal. Berman (1998) descreve as "crenças programáticas" da social-democracia na Alemanha e na Suécia a fim de mostrar sua consistência interna e seus efeitos diferenciados nos dois países. Cox (2004) delineia os contornos do que ele chama de "modelo escandinavo" de welfare, baseado nos pilares do universalismo, da solidariedade e da desmercantilização, a fim de mostrar como tais pilares impõem, em detrimento de ideais baseadas no laissez-faire, uma path 
dependence nas políticas sociais dos países nórdicos. Heclo (1974) acompanha o desenvolvimento de ideias sobre políticas sociais em campos específicos (desemprego, pensões e aposentadoria), descrevendo de maneira exaustiva as ideias que conduziram a discussão nessa área. Béland (2007) oferece uma visão dinâmica da política de segurança social americana, enfatizando os momentos significativos de mudança política. Arts \& Buier (2009) descrevem as ideias ligadas à sustentabilidade, biodiversidade e governança e analisam como elas modificaram a política florestal mundial a partir dos anos de 1980. Jacobs (2009) descreve as visões que influenciaram a política alemã de pensões públicas entre 1880 e 1950. E, por fim, Gofas (2001) descreve como a União Econômica e Monetária, órgão da União Europeia responsável pela convergência de políticas econômicas, institucionalizou ideias "alemãs" em seu processo de formação atual.

VI.2. Comparação

Ao alegarmos que ideias afetam decisões políticas estamos afirmando a existência de correlação entre o conteúdo dessas ideias e o que ocorre na política pública. Mas como saber se essa correlação não é espúria? O desenho de pesquisa comparativo, na medida em que permite controlar variáveis, produz conclusões mais robustas nesse campo. Para evidenciar o peso causal de ideias, recorre-se em geral à comparação entre casos positivos e negativos - o método da diferença, de Stuart Mill (1886) - ou o most similar systems design descrito por Przeworsky \& Teune (1982), em que casos similares em vários aspectos diferenciam-se quanto ao fenômeno a ser explicado e quanto a presença (ou ausência) de uma suposta variável explicativa. São inúmeros os autores que utilizam a comparação para ilustrar a correlação entre ideias e políticas públicas: alguns comparam políticas diferentes em um mesmo país (Walsh 2000; Goldstein 1988; Kingdon 2014; Larsen \& Andersen 2009; Ferejohn 1993); outros comparam políticas similares em um mesmo país (Mandelkern \& Shalev 2010; Ferejohn 1993) e ao longo do tempo (Alston et al., 2016); existem aqueles que comparam políticas similares em países distintos (Heclo 1974; Skogstad 1998; Cox 2001; Blyth 2002).

Berman (1998), por exemplo, buscou explicar por que a social-democracia sueca, diferentemente da alemã, foi capaz de produzir uma política de alianças antifascista. Segundo ela, a resposta encontra-se no legado ideacional específico de cada partido. Cox (2001), comparando Alemanha, Dinamarca e Holanda, pergunta-se por que os dois últimos países foram capazes de avançar em políticas de reforma do welfare state, enquanto que a Alemanha não. Hogan \& Feeney (2012) questionam sobre por que a presença de crises econômicas nos Estados Unidos e na Suécia produziu, no início dos anos 1980, resultados tão distintos como a clara redefinição da política econômica americana em direção ao neoliberalismo e a permanência da orientação social-democrata na Suécia. Skogstad (1998) discute a excepcionalidade da agricultura e o paradigma da assistência tendo em vista os casos americanos e europeu. Mandelkern \& Shalev (2010) examinam por que dois planos econômicos aparentemente similares obtiveram níveis de aceitação e sucesso diferentes em Israel. Dobbin (2004) investiga as diferentes participações do Estado no desenvolvimento industrial, considerando o desenvolvimento da política ferroviária na França e Estados Unidos. Bleich (1998) observa a aplicação da ideia de multiculturalismo nas políticas de educação inglesa e americana e alguns anos mais tarde analisa as políticas raciais na Grã-Bretanha e França (Bleich 2003). Hansen \& King (2001) se preocupam com políticas de migração e esterilização nos Estados Unidos e Grã-Bretanha, enquanto Bhatia \& Coleman (2003) dedicam atenção aos discursos utilizados nas políticas de saúde canadense e alemã no final dos anos 1980. White (2002) examina o legado do estado de 
bem-estar americano e canadense para explicar os níveis de prestação de cuidados à criança, demonstrando a importância das ideias como fatores causais no desenvolvimento de políticas públicas nos dois países.

\section{VI.3 Congruência}

A grande contribuição nesse ponto é, sem dúvida, de George (1979). Segundo este autor, o método da congruência tem duas características. Primeiramente, como já dissemos, trata-se de identificar da maneira mais sistemática possível as ideias de um determinado agente. Em seguida, o investigador procura mostrar se as preferências ideacionais do agente são consistentes com suas decisões. Nesse sentido, o método se caracteriza como dedutivo, pois se decisões correspondem às crenças, deduz-se que as decisões são o que são por causa das crenças. Obviamente, essa estratégia analítica coloca duas questões metodológicas importantes (George 1979; Yee 1996).

A primeira delas refere-se à natureza da correlação entre ideias e decisão, que pode ser espúria. Decisões podem ser o que são não por causa da crença, mas por outra razão qualquer, apesar da congruência entre elas. Esse problema se torna mais complexo se crenças forem ambíguas e, por isso, consistentes com mais de um tipo de decisão. Como atenuar esse problema? Há duas maneiras. Em primeiro lugar, é preciso realizar uma análise diacrônica. Como afirma George (1979, p.107), "a confiança de que a consistência entre crenças e ações tem significância causal é reforçada se for encontrada repetidamente numa sequência de decisões inter-relacionadas tomadas por um ator ao longo de um período". A segunda maneira, como já dissemos, é a comparação, que permite dar sustentabilidade ao raciocínio contrafatual de que as decisões observadas não teriam sido tomadas se as crenças em questão não estivessem presentes. Assim, se, por um longo período, constatamos reiteradamente a presença de determinadas ideias e de decisões a elas congruentes e, ao mesmo tempo, analisando outros casos similares, também por um longo período, constatamos que a ausência das mesmas ideias convive com a ausência de decisões semelhantes, temos razoáveis evidências para produzir uma "inferência causal" (Goldstein \& Keohane 1993). Ou seja, quanto mais a análise for estendida no tempo e mais o desenho de pesquisa se aproximar da comparação entre casos positivos e negativos, mais poderosas serão as inferências causais.

Muitos autores trabalham com esse procedimento, ainda que nem sempre o explicitem. Por exemplo, P. Hall (1986) mostra que, do pós-guerra até o final dos anos 1970, havia clara presença de ideias keynesianas na política econômica britânica e como ela se relacionava fortemente com atores que estavam à frente das principais agências do Estado. Goldstein (1988) procurou mostrar como determinadas orientações ideológicas predominam em diferentes políticas de comércio exterior nos Estados Unidos ao longo do tempo e como isso está relacionado com o desenho institucional (mais ou menos centrado no Executivo) e a ideologia dos decisores (mais ou menos propensos a defender o livre-comércio). Heclo (1974), por sua vez, analisa o desenvolvimento das políticas sociais na Grã-Bretanha e Suécia, do século XVII ao século XX, mostrando a relação entre ideias, políticas passadas e decisões presentes. Walsh (2000) também compara diferentes políticas (monetarismo, reforma do National Healrth Service (NHS) e relação entre governo central e local) na Grã-Bretanha ao longo do tempo, procurando mostrar como a existência (ou não) de congruência entre ideias e decisões tem a ver com arranjos institucionais e apoio social. Kurzer (2013) analisou como os princípios defendidos pela Comissão Estratégia de Emprego da União Europeia (EU), que exigia políticas de ativação do mercado de trabalho, afetaram a aposentadoria por invalidez na Holanda. Para o autor, os relatórios e as recomendações da UE 
geraram apoio (técnico e popular) às reformas, havendo clara congruência entre a nova lei de 2006 e os princípios da comissão. Acharya (2004) monitorou a penetração de normas internacionais em países da ASEAN, mostrando a relação entre ideias "estrangeiras" e a regulamentação das leis nacionais. Schmidt (2014) examinou a conformidade entre o "discurso coordenativo", acordado por líderes no âmbito decisório da UE, e o "discurso comunicativo" utilizado pelos estados-membros para comunicação com o mercado e a população em geral. A autora sugere que, em relação aos mercados especificamente, os líderes da UE propuseram soluções consideradas tardias e errôneas. Já em relação à população, Schmidt (2014) argumenta que a comunicação equivocada e enganosa abriu o campo político-ideológico aos extremos tanto da direita quanto da esquerda.

\section{VI.4. Process tracing}

19 Os atores sugerem que, além do process tracing, os
Mostrar que A é causa de B não significa, porém, revelar como A causa B ou, dito de outra forma, não evidencia o mecanismo causal da ação. A comparação e a congruência, que robustecem os enunciados causais acerca da relação entre ideias e decisões, não tornam visíveis os mecanismos que permitem ideias se traduzirem em decisões. A única forma de fazê-lo é recuperar o processo causal que liga A a B. Isso pode ser feito por meio de process tracing, que é uma densa narrativa do processo decisório com objetivo de apresentar sua "história causal" (Schmidt \& Radaelli 2004; George 1979; Campbell 2002; Yee 1996; Larsen \& Andersen 2009; Berman 1998; Jacobs 2015) ou documentar a "tapeçaria de histórias" produzida por determinada ideia (Wilkerson et al., 2015). Isso pode ser feito atentando-se para os micromecanismos do processo decisório. No entanto, é fácil perceber que tal método é de complexa utilização, já que os dados necessários para compor a narrativa dificilmente estão à disposição dos analistas e as fontes mais imediatamente acessíveis tendem a ser muito enviesadas (pois são quase exclusivamente oficiais). Cabe ao analista, portanto, ser muito reflexivo e lançar mão de um conjunto de procedimentos alternativos para gerar informações mais confiáveis, como entrevistas em profundidade com especialistas e decisores, jornais, surveys de opinião pública etc. (Goldstein \& Keohane 1993; Béland 2005; Jacobs 2015).

Metodologicamente, a conjugação do process tracing com densa descrição das ideias e com análise longitudinal pode gerar dados robustos que permitiriam dizer com aceitável grau de precisão como e por que as coisas ocorreram de certo modo e não de outro. A análise longitudinal é particularmente importante, pois fornece um hoop test capaz de revelar algo necessário à condição de validade de qualquer teoria ideacional, isto é, que ideias variam independentemente das condições materiais do contexto em análise. Como são estudos que lidam com um pequeno número de casos, a estratégia qualitativa de apresentar uma densa descrição histórica e longitudinal da conexão entre ideias e escolhas políticas é tecnicamente viável e metodologicamente aconselhável (Lieberman 2002; Yee 1996; Jacobs 2015).

Schmidt \& Radaelli (2004) utilizam o process tracing para analisar as modificações institucionais e políticas ocorridas na Europa pós-União Europeia. Os autores delineiam os principais fatores identificados na literatura especializada e, em seguida, procuram estabelecer relações causais entre aprendizagem institucional, mudanças políticas e discursos no processo de integração europeia. Utilizando procedimentos semelhantes, Béland \& Cox (2016) rastrearam como três ideias (sustentabilidade, inclusão social e solidariedade) foram criativamente empregadas para construir novas coalizões políticas em escala mundial ${ }^{19}$. Larsen \& Anderson (2009) buscam acompanhar, na Dinamarca, a influência de novas ideias econômicas em três áreas: seguro-desemprego, 
estudiosos também podem analisar ideias examinando seu ciclo de vida e explorar como e se tais ideias deixaram de ser "ímãs" para coalizões ao longo do tempo. aposentadoria precoce e tributação. Bleich (2003) segue o desenvolvimento ideacional que deu origem a distintas políticas raciais na Grã-Bretanha e França durante a década de 1960. O mesmo foi realizado por Hansen \& King (2001) ao analisar ideias eugênicas e as políticas de migração e esterilização nos Estados Unidos e Grã-Bretanha (Hansen \& King 2001). Helgadóttir (2016) mostra, por meio do procedimento de rastreamento, como um conjunto específico de ideias econômicas italianas, formuladas pela primeira vez na primeira metade do século XX, desempenhou importante papel na formulação de respostas à Grande Depressão, estabelecendo os contornos da doutrina de "austeridade expansionista" que pregava cortes de despesas públicas como motor para crescimento econômico. Walsh (2000) lança mão do process tracing para entender o modo pelo qual a presença de uma ideia se vincula ao seu sucesso no processo decisório; com muito mais fôlego Heclo (1974) acompanha o desenvolvimento das políticas sociais durante longo período na Grã-Bretanha e Suécia. Kingdon (2014) realiza magistral acompanhamento da visibilidade pública de ideias, sua presença entre agentes políticos governamentais e não governamentais, sua recepção entre burocratas e especialistas e, por fim, seus impactos decisórios. Berman (1998) acompanha passo a passo o processo histórico que levou a social-democracia sueca a desenvolver uma perspectiva própria, bastante diferente da de sua congênere alemã, em relação a quatro pontos programáticos fundamentais (o marxismo, a democracia, a transição para o socialismo e a luta de classes). Em seguida, mostra como essas crenças programáticas viabilizaram, no caso da Suécia, a luta pelo sufrágio universal e a formulação de uma aliança de classe que resultou na introdução precoce do keynesianismo naquele país.

Apesar do predomínio de técnicas qualitativas, existem algumas tentativas de aplicar técnicas quantitativas no uso do process tracing. Wilkerson et al. (2015), por exemplo, buscaram traçar a evolução de ideias sobre o Patient Protection and Affordable Care Act (PPACA) no processo legislativo americano. Para tanto, utilizam o método de reutilização de texto (text reuse approach) para rastrear o progresso do discurso democrata e republicano; Chwieroth (2007) também procurou acompanhar, de forma quantitativa, a influência de ideias do Fundo Monetário Internacional (FMI) na abertura de conta de capital, ou seja, na liberalização financeira de diversos países do mundo; Kogut \& Macpherson (2011) usam testes estatísticos para medir o impacto das ideias dos economistas americanos nas políticas de privatização e de independência do Banco Central. Isso para não nos referirmos aos já tradicionais procedimentos quantitativos da estatística léxica utilizada para identificar as estruturas mentais subjacentes aos discursos, descritos por Prost (2003).

Enfim, como usualmente ocorre nas ciências sociais, é sempre muito difícil apresentar a smoking gun de uma relação causal. A situação se repete no campo de estudo em questão. Por essa razão, parece-nos que a apresentação de achados robustos acerca do impacto de ideias exige o uso combinado da análise discursiva, da comparação, da congruência e do process tracing. Essa combinação pode permitir ao analista responder às três questões formuladas por Parsons $(1965)^{20}$, cujas respostas seriam necessárias para afirmar (ou negar) o impacto causal de configurações ideacionais no interior de um sistema social.

\section{Conclusões}

\footnotetext{
${ }^{20}$ A saber: (1) existem diferenças entre ideias de grupos sociais distintos no interior de determinado sistema social?; (2) existe relação entre essas diferenças e algum evento no sistema
}

Ideais importam. Seria estranho imaginar que aquilo que os operadores das instituições políticas pensam sobre o mundo não afetasse suas ações. Pensar em ações desprovidas de ideias, na verdade, parece-nos impensável. Com base na literatura, apresentamos, primeiro, a interlocução crítica entre as várias vertentes da teoria institucionalista. Procuramos mostrar como essas diversas correntes inserem as ideias nos seus modelos explicativos. Discutimos os limites e 
social?; (3) essa relação não se deve a nenhuma outra variável independente? vantagens das diferentes propostas e apresentamos, de acordo com a literatura, os avanços teóricos propiciados pelo chamado institucionalismo discursivo. Em seguida, apontamos como a literatura que defende a inclusão das ideias na análise dos fenômenos políticos identifica várias dimensões ideacionais, como ela hierarquiza ideias em função de sua capacidade estruturante e de sua abrangência. Discutimos ainda as circunstâncias (político-institucionais, de incerteza e de path dependence) que favorecem os impactos ideacionais e os modos pelos quais as ideias afetam as decisões (definindo problemas, selecionando alternativas, viabilizando coalizões). Por fim, apresentamos os procedimentos metodológicos (descrição, comparação, congruência e process tracing) utilizados pelos pesquisadores para produzirem enunciados causais robustos nessa área de estudo, comprovando a efetividade da análise ideacional.

A defesa da explicação ideacional frente as demais correntes teóricas, porém, não implicou adotar a posição de que as ideias seriam o único fator explicativo dos fenômenos políticos. Isso seria tão absurdo quanto qualquer outro tipo de reducionismo que assombra as ciências sociais de tempos em tempos. Os próprios adeptos da virada ideacional reconhecem que o idealismo é um perigo a se evitar e afirmam que o impacto das ideias ocorre sempre acompanhado do peso dos fatores estruturais. Mas se as ideias são apenas uma causa entre outras, quais seriam de fato os avanços que a virada ideacional teria propiciado para a nossa disciplina? Sem querer responder plenamente a essa questão, acreditamos ser possível indicar três pontos importantes que deveriam fazer parte de qualquer resposta acabada a ela. Apresentamo-los separadamente a seguir.

O primeiro deles foi sumarizado na seção III do presente artigo. Acreditamos que a perspectiva ideacional pode ser analiticamente rentável na medida em que professa a autonomia das ideias frente aos interesses e, por extensão, a sua condição de variável explicativa central para entender os processos políticos. Como consequência dessa posição, confere centralidade aos atores e à sua capacidade de reflexão, rejeitando a posição pouco plausível da intercambialidade dos indivíduos. Ao fazer isso, porém, não cai numa antinomia pobre e simplista entre o "mundo material" e o "mundo ideal". Os autores vinculados a essa literatura jamais deixaram de pensar como determinadas condições sociais e políticas são importantes condicionantes da eficácia de uma ideia. Talvez nada possa sintetizar de forma mais adequada essa posição intermediária entre um materialismo tacanho e um idealismo delirante do que a velha, mas verdadeira, afirmação de que os homens fazem a sua própria história, ainda que em circunstâncias não escolhidas por eles. Para essa literatura, é pouco plausível pensar que se faça história sem ideias.

Nesse sentido, apesar de explicitamente recusarem qualquer monismo explicativo que pudesse redundar num idealismo pouco crível, pode-se dizer que explicações ideacionais fornecem aquele "tropeço" causal a que se referia Bloch (2002). Ou seja, é inegável que as condições estruturais têm o poder de tornar alguns eventos mais prováveis do que outros. No entanto, por mais fortes que sejam tais condicionantes, ainda assim um leque de escolhas potenciais estará à disposição dos atores políticos e a escolha efetivamente feita pode ser, em grande medida, explicada pelas ideias que eles têm acerca do que fazer em determinado momento. Os estudos comparativos aqui listados mostram amplamente como explicações "objetivistas", que procuram derivar as decisões dos atores de suas posições estruturais (materiais ou institucionais), mostram-se incapazes de explicar adequadamente casos estruturalmente similares, porém distintos quanto aos resultados políticos.

Em segundo lugar, a plausibilidade da proposição acerca do papel causal das ideias não era cientificamente suficiente. Era preciso mostrar, primeiro, que 
ideias podem ser variáveis explicativas de direito próprio, isto é, não redutíveis a outras variáveis contextuais, para, em seguida, revelar os procedimentos que permitissem operacionalizar essa proposição empiricamente. Nesse sentido, a literatura em questão se esforçou por combinar descrição, diacronia e comparação de modo a produzir enunciados causais robustos. Ciente do caráter fugidio do seu objeto e das dificuldades de mensurá-lo adequadamente, a literatura da virada ideacional cercou-se de procedimentos que poderiam aumentar a força de suas proposições. Por essa razão, quase todos os trabalhos, e mais especificamente os livros, são marcados por longas e densas descrições dos fenômenos a serem explicados, assumem um desenho conscientemente comparativo e mantêm um intenso diálogo com as explicações alternativas. Os autores filiados a essa corrente parecem querer dizer que não é possível fazer ciência sem descrição, sem história e sem comparação.

Por fim, parece-nos que a explicação ideacional tem a capacidade de incorporar variáveis importantes para outros modelos explicativos. Para ficar num único exemplo, é impossível pensar a path dependence intelectual sem levar em consideração o processo de institucionalização das ideias e os efeitos de longo prazo que o acompanham. Continuidades ideacionais, portanto, não podem ser pensadas separadamente de instituições. Não por outra razão, vários autores filiam essa literatura à família das teorias institucionalistas, como vimos. No entanto, por mais socialmente significativo que seja o processo de reprodução institucionalizada das ideias, a introdução de variáveis ideacionais no modelo explicativo permite levar em consideração outros dois aspectos importantes para entender as instituições e seu funcionamento: de um lado, suas origens e o quadro mental dos seus construtores, que terminará por moldar a forma final assumida por elas; de outro, os embates discursivos que ocorrem dentro e fora das instituições e que são capazes de alterá-las, refundá-las ou mesmo criar novas instituições. O institucionalismo da virada ideacional se faz presente por uma preocupação recorrente com a origem das instituições, o seu tipo, a sua reprodução no tempo e sua transformação. Desse modo, pretende explicar por que as coisas são como são, por que continuam a sê-lo e por que mudam.

Renato Monseff Perissinotto (monseff@gmail.com) é Doutor em Ciências Sociais pela Universidade Estadual de Campinas (Unicamp) e professor do Departamento de Ciência Política da Universidade Federal do Paraná (UFPR). É pesquisador do CNPq, nível 2. Vínculo institucional: Programa de Pós-Graduação em Ciência Política, UFPR, Curitiba, PR, Brasil.

Michelli Gonçalves Stumm (michellistumm@gmail.com) é Mestra em Sociologia pela Universidade Federal do Paraná e Doutoranda em Ciência Política pela mesma universidade. Vínculo Institucional: Programa de Pós-Graduação em Ciência Política, UFPR, Curitiba, PR, Brasil.

\section{Referências}

Acharya, A., 2004. How Ideas Spread: Whose Norms Matter? Norm Localization and Institutional Change in Asian Regionalism. International Organization, 58(2), pp.239-275. DOI: 10.1017/s0020818304582024

Alston, L.J. et al., 2016. Brazil in Transition: Beliefs, Leadership and Institutional Change. Princeton: Princeton University Press.

Anderson, B., 1991. Comunidades imaginadas. São Paulo: Companhia das Letras.

Aragão, L.G.T., 2011. Ideias, interesses e instituições na formação de agendas de políticas públicas: o caso do programa de Economia Solidária Ideias , Interesses e Instituições na formação de agendas de políticas públicas?: o caso do programa de Economia Solidária. Brasília: Universidade de Brasília.

Arts, B. \& Buizer, M., 2009. Forests, Discourses, Institutions. Forest Policy and Economics, 11(5-6), pp.340-347. DOI: 10.1016/j.forpol.2008.10.004

Barcelos, M., 2015. Ideias, Agendas e Políticas Públicas: um estudo sobre a área de biocombustível no Brasil. Porto Alegre: Universidade Federal do Rio Grande do Sul.

Béland, D., 2005. Ideas and Social Policy: An Institutionalist Perspective. Social Policy and Administration, 39(1), pp.1-18. DOI: $10.1111 / \mathrm{j} .1467-9515.2005 .00421 . x$ 
2005. Ideas and Social Policy: An Institutionalist Perspective. Social Policy \& Administration, 39(1), pp.1-18. DOI: 10.1111/j.1467-9515.2005.00421.x , 2007. Ideas and Institutional Change in Social Security: Conversion, Layering, and Policy Drift. Social Science Quarterly, 88(1), pp.20-38. DOI: 10.1111/j.1540-6237.2007.00444.x_

,2009a. Gender, Ideational Analysis, and Social Policy. Social Politics, 16(4), pp.558-581. DOI: 10.1093/sp/jxp017

2009b. Ideas, Institutions, and Policy Change. Journal of European Public Policy, 16(5), pp.701-718. DOI:

10.1163/2468-1733_shafr_sim290020020

, 2010. The Idea of Power and the Role of Ideas. Political Studies Review, 8(2), pp.145-154. DOI: 10.1111/j.1478-9302.2009.00199.x

Béland, D. \& Cox, R.H., 2016. Ideas as Coalition Magnets: Coalition Building, Policy Entrepreneurs, and Power Relations. Journal of European Public Policy, 23(3), pp.428-445. DOI: 10.1080/13501763.2015.1115533

Béland, D. \& Hacker, J.S., 2004. Ideas, Private Institutions and American Welfare State "Exceptionalism": The Case of Health and Old-Age Insurance, 1915-1965. International Journal of Social Welfare, 13(1), pp.42-54. DOI: $10.2139 /$ ssrn. 1676010

Berman, S., 1998. The Social Democratic Moment. London: Harvad University Press. , 2001. Ideas, Norms, and Culture in Political Analysis. The Journal of Comparative Politics, 33(2), pp.231-250. DOI: $10.2307 / 422380$

,2013. Ideational Theorizing in the Social Sciences since "Policy Paradigms, Social Learning, and the State." Governance: An International Journal of Policy, Administration, and Institutions, 26(2), pp.217-237. DOI: 10.1111/gove. 12008

Bhatia, V.D. \& Coleman, W., 2003. Ideas and Discourse: Reform and Resistance in the Canadian and German Health Systems. Canadian Journal of Political Science, 36(4), pp.715-739. DOI: 10.1017/s0008423903778822

Bleich, E., 1998. From International Ideas to Domestic Policies: Educational Multiculturalism in England and France. Comparative Politics, 31(1), pp.81-100. DOI: 10.2307/422107

,2003. Race Politics in Britain and France: Ideas and Policymaking since the 1960s. New York: Cambridge University Press.

Bloch, M., 2002. Apologia da história ou o ofício do historiador. Rio de Janeiro: Jorge Zahar Editor.

Blyth, M., 1997. "Any More Bright Ideas?" The Ideational Turn of Comparative Political Economy. Comparative Politics, 29(2), p.229. DOI: $10.2307 / 422082$

, 2001. The Transformation of the Swedish Model: Economic Ideas, Distributional Conflict, and Institutional Change. World Politics, 54(1), pp.1-26. DOI: 10.1353/wp.2001.0020

,2002. Great Transformations: Economic Ideas and Institutional Change in the Twentieth Century. Cambridge: Cambridge University Press.

, 2003. Structures Do Not Come with an Instruction Sheet: Interests, Ideas, and Progress in Political Science. Perspectives on Politics, 1(4), pp.695-706. DOI: 10.1017/s1537592703000471

Bourdieu, P., 1989. A gênese dos conceitos de habitus e de campo. In ___, ed. O poder simbólico. Lisboa: Difel.

Campbell, J.L., 1998. Institutional Analysis and the Role of Ideas in Political Economy. Theory and Society, 27(3), pp.377-409.

,2002. Ideas, Politics, and Public Policy. Annual Review of Sociology, 28(1), pp.21-38. DOI: 10.2307/422352

Chartier, R., 2003. Origens culturais da Revolução Francesa. São Paulo: Editora da Unesp.

Chwieroth, J.M., 2007. Testing and Measuring the Role of Ideas?: The Case of Neoliberalism in the International Monetary Fund. International Studies Quarterly, 51, pp.5-30. DOI: 10.1111/j.1468-2478.2007.00437.x

Converse, P.E., 1964. The Nature of Belief Systems in Mass Publics. In D.E. Apter, ed. Ideology and Discontent. New York: The Free Press.

Costa, S.F., 2011. Dust of ideas in the wind ou como pequenos grãos de ideias se propagam: o impacto do ambiente internacional e as pressões internas sobre o padrão na oferta de políticas públicas no Brasil e na Colômbia. João Pessoa: Universidade Estadual da Paraíba.

Cox, R.H., 2004. The Path-Dependency of an Idea: Why Scandinavian Welfare States Remain Distinct. Social Policy and Administration, 38(2), pp.204-219. DOI: 10.1111/j.1467-9515.2004.00386.x

,2001. The Social Construction of an Imperative: Why Welfare Reform Happened in Denmark and the Netherlands but not in Germany. World Politics, 53(3), pp.463-498. DOI: 10.1353/wp.2001.0008

Cox, R.H. \& Béland, D. 2013. Valence, Policy Ideas, and the Rise of Sustainability. Governance, 26(2), pp.307-328. DOI: 10.1111 /gove. 12003

Crawford, N.C., 2006. How Previous Ideas Affect Later Ideas. In R.E. Goodin \& C. Tilly, eds. The Oxford Handbook of Contextual Political Analysis. Oxford: Oxford University Press.

Desai, R., 1994. Second-hand Dealers in Ideas: Think-tanks and Thatcherite Hegemony. New Left Review, 203, pp.27-64.

Dobbin, F., 2004. How Institutions Create Ideas: Notions of Public and Private Efficiency from Early French and American Railroading. L'Année de la Régulation, 8, pp.15-50.

Engels, F., s.d. Carta a Bloch. In K. Marx \& F. Engels. Obras Escolhidas Marx/Engels. V. 1. São Paulo: Alfa-Ômega.

Ferejohn, J., 1993. Structures and Ideology: Change in Parliament in Early Stuart England. In J. Golstein \& R. Keohane, eds. Ideas and Foreign Policy: Beliefs, Institutions and Political Change. Ithaca: Cornell University Press.

Friedrich, C.J., 1974. Tradição e autoridade em Ciência Política. Rio de Janeiro: Jorge Zahar Editor. 
George, A.L., 1979. The Causal Nexus between Cognitive Beliefs and Decision-Making Behavior. The "Operational Code" Belief System. In L.S. Falkowski, ed. Psychological Models in International Politics. Colorado: Westview Press.

Gofas, A., 2001. Ideas and Interests in the Construction of EMU: Beyond the Rationalist Bias of the New Ideational Orthodoxy. CSGR Working Paper, 76/01. Centre for the Study of Globalisation and Regionalisation (CSGR), University of Warwick.

Goldstein, J., 1988. Ideas, Institutions, and American Trade Policy. International Organization, 42(1), pp.179-217. DOI: 10.1093/acprof:oso/9780199557752.003.0002 , 1993. Ideas, Interests, and American Trade Policy, Ithaca: Cornell University Press.

Goldstein, J. \& Keohane, R.O., 1993. Ideas and Foreign Policy: An Analytical Framework. In J. Goldstein \& R.O. Keohane, eds. Ideas and Foreign Policy: Beliefs, Institutions and Political Change. Ithaca: Cornell University Press.

Gourevitch, P., 1986. Politics in Hard Times: Comparative Responses to International Economic Crises. Ithaca: Cornell University Press.

, 1989. Keynesian Politics: The Political Sources of Economic Policy Choices. In P. Hall, ed. The Political Power of Economic Ideas. Keynesianism across Nations. Princeton: Princeton University Press.

Grisa, C., 2012. Políticas públicas para a Agricultura Familiar no Brasil: produção e institucionalização das ideias. Rio de Janeiro: Universidade Federal Rural do Rio de Janeiro.

Hall, J., 1993. Ideas and the Social Sciences. In J. Goldstein \& R. O. Keohane, eds. Ideas and Foreign Policy: Beliefs, Institutions and Political Change. Ithaca: Cornell University Press.

Hall, P., 1986. The Politics of State Intervention in Britain and France. Oxford: Oxford University Press. 1989. The Political Power of Economic Ideias: Keynesianism Across Nations. New Jersey: Cambridge University Press.

, 1993. Policy Paradigms, Social Learning, and the State: The Case of Economic Policymaking in Britain. Comparative Politics, 25(3), pp.275-296. DOI: 10.2307/422246

Hall, P. \& Taylor, R., 2003. As três versoes do neoinstitucionalismo. Lua Nova, 58, pp.194-223.

Halpern, N., 1993. Creating Socialist Economies: Stalinist Political Economy and the Impact of Ideas. In J. Goldstein \& R. Keohane, eds. Ideas and Foreign Policy: Beliefs, Institutions and Political Change. Ithaca: Cornell University Press.

Hansen, R. \& King, D.S., 2001. Eugenic Ideas, Political Interests and Policy Variance: immigration and sterilization policy in Britain and the U.S. World Politics, 53(3), pp.237-263. DOI: 10.1353/wp.2001.0003

Hay, C., 1996. Narrating Crisis: The Discursive Construction of the "Winter of Discontent". Sociology, 30(2), pp.253-277. DOI: $10.1177 / 0038038596030002004$

,2011. Ideas and constructions of interests. In D. Béland \& R.H. Cox, eds. Ideas and Politics in Social Sciences. Oxford: Oxford University Press.

, 2008. Constructivist Institutionalism. In S.A. Binder; R.A.W. Rhodes \& B.A. Rockman, eds. The Oxford Handbook of Political Institutions. New York: Oxford University Press.

Heclo, H., 1974. Modern Social Politics in Britain and Sweden: From Relief to Income Maintenance. In H. Heclo, ed. New Haven-London: Yale University Press.

Helgadóttir, O., 2016. The Bocconi Boys Go to Brussels: Italian Economic Ideas, Professional Networks and European Austerity. Journal of European Public Policy, 23(3), pp.392-409. DOI: 10.1080/13501763.2015.1106573

Hirschman, A. O., 1979. The Turn to Authoritarianism in Latin America and the Search for its Economic Determinants In D. Collier (ed.), The New Authoritarianism in Latin America Princeton: Princeton University Press, pp.61-98.

Hochschild, J.L., 2006. How Ideas Affect Actions. In R.E. Goodin \& C. Tilly, eds. The Oxford Handbook of Contextual Political Analysis. Oxford: Oxford University Press.

Hogan, J. \& Feeney, S., 2012. Crisis and Policy Change: The Role of the Political Entrepreneur. Risk, Hazards \& Crisis in Public Policy, 4(2), pp.1-16. DOI: 10.1515/1944-4079.1108

Hogan, J. \& O’Rourke, B., 2014. The Critical Role of Ideas: A Discursive Institutionalist Approach to Understanding Change in Irishi Industrial Policy. In Midwest Political Science Association Annual Conference. Chicaco.

Ikenberry, G.J., 1993. Creating Yestarday's New World Order: Keynesian "New Thinking” and the Anglo-American Postwar Settlement. In J. Goldstein \& R. Keohane, eds. Ideas and Foreign Policy: Beliefs, Institutions and Political Change. Ithaca: Cornell University Press.

Immergut, E.M., 1998. The Theoretical Core of the New Institutionalism. Politics \& Society, 26(1), pp.5-34. DOI: $10.1177 / 0032329298026001002$

Jacobs, A.M., 2009. How Do Ideas Matter?: Mental Models and Attention in German Pension Politics. Comparative Political Studies, 42(2), pp.252-279. DOI: 10.1177/0010414008325283

2015. Process-Tracing the Effects of Ideas. In A. Bennett \& J. Checkel, eds. Process Tracing in the Social Sciences: From Metaphor to Analytic Tool. Cambridge: Cambridge University Press.

Jacobsen, J.K., 1995. Much Ado about Ideas: The Cognitive Factor in Economic Policy. World Politics, 47(2), pp.283-310. DOI: $10.1017 / \mathrm{s} 0043887100016117$

Jaiani, V. \& Whitford, A.B., 2011. Policy Windows, Public Opinion and Policy Ideas: The Evolution of No Child Left Behind. Quality Assurance in Education, 19(1), pp.8-27. DOI: 10.1108/09684881111107735

James, S., 1993. The Idea Brokers: The Impact of Think Tanks on British Government. Public Administration, 71(4), pp.491-506. DOI: 10.1111/j.1467-9299.1993.tb00988.x

Kangas, O.E.; Niemelä, M. \& Varjonen, S., 2014. When and Why Do Ideas Matter? The Influence of Framing on Opinion Formation and Policy Change. European Political Science Review, 6(1), pp.73-92. DOI: 10.1017/s1755773912000306 
Kindleberger, C.P., 1975. The Rise of Free Trade in Western Europe, 1820-1875. The Journal of Economic History, 35(1), pp.20-55. DOI: 10.4159/harvard.9780674418875.c3

Kingdon, J.W., 2014. Agendas, Alternatives, and Public Policies. Essex: Pearson Education.

Kogut, B. \& MacPherson, J.M., 2011. The Mobility of Economists and the Diffusion of Policy Ideas: The Influence of Economics on National Policies. Research Policy, 40, pp.1307-1320. DOI: 10.1016/j.respol.2011.06.008

Krasner, S.D., 1993. Westphalia and All That. In J. Goldstein \& R. Keohane, eds. Ideas and Foreign Policy: Beliefs, Institutions and Political Change. Ithaca: Cornell University Press.

Kurzer, P., 2013. The Politics of Ideas in Reforming the Dutch Disability Fund. Governance, 26(2), pp.283-305. DOI: 10.1111 /gove. 12005

Larsen, C.A. \& Andersen, J.G., 2009. How New Economic Ideas Changed the Danish Welfare State: The Case of Neoliberal Ideas and Highly Organized Social Democratic Interests. Governance, 22(2), pp.239-261. DOI: 10.1111/j.1468-0491.2009.01434.x

Lieberman, R.C., 2002. Ideas, Institutions, and Political Order: Explaining Political Change. The American Political Science Review, 96(4), pp.697-712. DOI: 10.1017/s0003055402000394

Lukic, M.R. \& Tomazini, C., 2014. Abordagens cognitivas na análise de políticas públicas na américa latina: um novo olhar sobre velhas questões? In IX Encontro da ABCP. Brasília.

Mahoney, J. \& Thelen, K., 2010. Institutional Change. Ambiguity, Agency, and Power Cambridge: Cambridge Universty Press.

Mandelkern, R. \& Shalev, M., 2010. Power and the Ascendance of New Economic Policy Ideas: Lessons from the 1980s Crisis in Israel. World Politics, 62(3), pp.459-495. DOI: 10.1017/s0043887110000109

Marx, K., s.d. O 18 Brumário de Luiz Bonaparte. In K. Marx \& F. Engels. Obras Escolhidas Marx/Engels. V. 1. São Paulo: Alfa-Ômega.

Mehta, J., 2011. The Varied Roles of Ideas in Politics: From "Whether" to "How”. In D. Béland \& R.H. Cox, eds. Ideas and Politics in Social Sciences. Oxford: Oxford University Press.

Mohr, J.W., 1998. Measuring Meaning Structures. Annual Review of Sociology, 24(1), pp.345-370. DOI: 10.1146/annurev.soc.24.1.345.

Moore Jr., B., 1951. Soviet Politics. The Dilemma of Power. The Role of Ideas in Social Change. Cambridge, MA: Harvard University Press.

Novelli, J.M.N., 2001. Instituições, política e ideias econômicas: o caso do Banco Central do Brasil (1965-1998). São Paulo: Fapesp/Annablume.

Panizza, F. \& Miorelli, R., 2013. Taking Discourse Seriously: Discursive Institutionalism and Post-structuralist Discourse Theory. Political Studies, 61(2), pp.301-318. DOI: 10.1111/j.1467-9248.2012.00967.x

Parsons, C., 2000. Domestic Interests, Ideas and Integration: Lessons from the French Case. Journal of Common Market Studies, 38(1), pp.45-70. DOI: 10.1111/1468-5965.00208

Parsons, T., 1965. The Role of Ideas in Social Action. In T. Parsons, ed. Essays in Sociological Theory. London: Free Press.

Perissinotto, R. \& Szwako, J., 2017. Movimentos sociais como teóricos políticos: Wolin, ideias e políticas públicas. Lua Nova, n. 102, p. 231-263. DOI: 10.1590/0102-231263/102

Pierson, P., 2000. Increasing Returns, Path dependency, and Study of Politics. American Political Science Review, 94(2), pp.251-267. DOI: $10.2307 / 2586011$

Price, R., 2006. Detecting Ideas and Their Effects. In R.E. Goodin \& C. Tilly, eds. The Oxford Handbookfor Contextual Political Analysis. Oxford: Oxford University Press.

Prost, A., 2003. As palavras. In R. Rémond, ed. Por uma história política. Rio de Janeiro: Editora da FGV.

Przeworsky, A. \& Teune, H., 1982. The Logic of Comparative Social Inquiry. Malabar: Krieger Publishing Company.

Rich, A., 2005a. Think-tanks, Public Policy and the Politics of Expertise. Cambridge: Cambridge University Press. ,2005b. War of Ideas: Why Mainstream and Liberal Foundations and the Think Tanks They Support Are Losing in the War of Ideas in American Politics. Stanford Social Innovation Review, Spring, pp.18-25.

Rocha, C. V., 2011. Ideas in the Making of an Educational Reform Agenda. Ensaio, 19(70), pp.191-218.

Rueschemeyer, D., 2006. How and Why Ideas Matter. In R.E. Goodin \& C. Tilly, eds. The Oxford Handbook of Contextual Political Analysis. Oxford: Oxford University Press.

Schmidt, V.A., 2008. Discursive Institutionalism: The Explanatory Power of Ideas and Discourse. Annual Review of Political Science, 11(1), pp.303-326. DOI: 10.1146/annurev.polisci.11.060606.135342

,2010. Taking Ideas and Discourse Seriously: Explaining Change Through Discursive Institutionalism as the Fourth "New Institutionalism". European Political Science Review, 2(1), pp.1-25. DOI: 10.1017/s175577390999021x , 2011. Reconciling Ideas and Institutions through Discursive Institutionalism. In D. Béland \& R.H. Cox, eds. Ideas and Politics in Social Science Research. Oxford: Oxford University Press.

, 2013. Arguing about the Eurozone Crisis: A Discursive Institutionalist Analysis. Critical Policy Studies, 7(4), pp.455-462. DOI: 10.1080/19460171.2013.851314

, 2014. Speaking to the Markets or to the People? A Discursive Institutionalist Analysis of the EU's Sovereign Debt Crisis. The British Journal of Politics \& International Relations, 16(1), pp.188-209. DOI: 10.1111/1467-856x.12023

Schmidt, V.A. \& Radaelli, C.M., 2004. Policy Change and Discourse in Europe: Conceptual and Methodological Issues. West European Politics, 27(2), pp.183-210. DOI 10.1080/0140238042000214874 
Schmidt, V.A. \& Thatcher, M., 2013. Theorizing Ideational Continuity: The Resilience of Neo-Liberal Ideas in Europe. In V.A. Schmidt \& M. Thatcher, eds. Resilient Liberalism in Europe's Political Economy. Cambridge: Cambridge University Press.

Seabrooke, L. \& Wigan, D., 2016. Powering Ideas through Expertise: Professionals in Global Tax Battles. Journal of European Public Policy, 23(3), pp.357-374. DOI: 10.1080/13501763.2015.1115536

Searle, J.R., 2002. Intencionalidade. São Paulo: Editora Martins Fontes.

Sikkink, K., 1991. Ideas and Institutions. Developmentalism in Brazil and Argentina, Ithaca: Cornell University Press.

Skogstad, G., 1998. Ideas, Paradigms and Institutions: Agricultural Exceptionalism in the European Union and the United States. Governance, 11(4), pp.463-490. DOI: 10.1111/0952-1895.00082

Sola, L., 1998. Ideias econômicas, decisões políticas São Paulo: Edusp/Fapesp.

Steinmo, S.; Thelen, K. \& Longstreth, F., 1992. Structuring Politics: Historical Institutionalism in Comparative Analysis. Cambridge: Cambridge University Press.

Stuart Mill, J., 1886. System of Logic Ratiocinative and Inductive Being a Connected View of the Principles of Evidence and the Methods of Scientific Investigation, London: Longmans, Green, and Co.

Sumiya, L.A., 2015. A hora da alfabetização: atores, ideias e instituições na construção do PAIC-CE. Natal: Universidade Federal do Rio Grande Norte.

Thelen, K. \& Steinmo, S., 1994. Historical Institutionalism and Comparative Politics. In S. Steinmo; K. Thelen \& F. Longstreth, eds. Structuring Politics: Historical Institutionalism in Comparative Analysis. Cambridge: Cambridge University Press.

Tocqueville, A., 2003. O antigo regime e a revolução. São Paulo: Editora Martins Fontes.

Tomazini, C. \& Leite, C.K., 2016. Programa Fome Zero e o paradigma da segurança alimentar: ascensão e queda de uma coalizão? Revista de Sociologia e Política, 24(58), pp.13-30. DOI: 10.1590/1678-987316245801

Walker, S.G., 1990. The Evolution of Operational Code Analysis. Political Psychology, 11(2), pp.403-418. DOI: $10.2307 / 3791696$

Walsh, J.I., 2000. When Do Ideas Matter?: Explaining the Successes and Failures of Thatcherite Ideas. Comparative Political Studies, 33(4), pp.483-516. DOI: 10.1177/0010414000033004003

Weber, M., 1981. The Social Psychology of World Religions. In H.H. Gerth \& C.W. Mills, eds. From Max Weber. Essays in Sociology. Oxford: Oxford University Press.

White, L.A., 2002. Ideas and the Welfare State: Explaining Child Care Policy Development in Canada and the United States. Comparative Political Studies, 35(6), pp.713-743. DOI: 10.1177/0010414002035006004

Wilkerson, J.; Smith, D. \& Stramp, N., 2015. Tracing the Flow of Policy Ideas in Legislatures: A Text Reuse Approach. American Journal of Political Science, 59(4), pp.943-956. DOI: 10.1111/ajps.12175

Wuthnow, R., 1989. Community of Discourse. Ideology and Social Structure in the Reformation, the Enlightenment, and European Socialism. Cambridge: Harvard University Press.

Yee, A.S., 1996. The Causal Effects of Ideas on Policies. International Organization, 50(1), pp.69-108. DOI: $10.1017 / \mathrm{s} 0020818300001673$ 


\section{The Ideational Turn: When and How Ideas Matter}

\section{Abstract}

This bibliographic essay analyzes the literature known as "ideational turn". Its purpose is, firstly, to summarize the criticisms of this literature to the institutionalist perspectives with which it dialogues; Secondly, to systematize its theoretical advantages and, finally, to identify the methodological tools used by researchers affiliated to it. The essay is based on the analysis of a wide range of books and articles published on the subject mostly over the last twenty years. Through this bibliographic review, we were able to show how the literature of the ideational turn allows us to include ideas in the explanations of political phenomena. The inclusion of ideas, in turn, requires a pluralistic methodological stance that can represent important advances for political science.

Keywords ideational turn; discursive institutionalism; contructivism; comparison; process tracing.

This is an Open Access article distributed under the terms of the Creative Commons Attribution Non-Commercial License which permits unrestricted non-commercial use, distribution, and reproduction in any medium provided the original work is properly cited. 